\title{
A novel fixture for determining the tension/compression-shear failure envelope of multidirectional composite laminates
}

Khong Wui Gan*, a,b, Tobias Laux ${ }^{\mathrm{b}}$, Siavash T. Taher ${ }^{\mathrm{c}}$, Janice M. Dulieu-Barton ${ }^{\mathrm{b}}$, Ole T. Thomsen ${ }^{\mathrm{b}}$

${ }^{a}$ Faculty of Engineering and the Environment, University of Southampton Malaysia Campus (USMC), Kota Ilmu Educity @ Iskandar, 79200 Iskandar Puteri, Johor, Malaysia

${ }^{\mathrm{b}}$ Faculty of Engineering and the Environment, University of Southampton, Highfield, SO17 1BJ, Southampton, UK

c Department of Mechanical and Manufacturing Engineering, Aalborg University, Denmark

* Corresponding author. E-mail: K.W.Gan@soton.ac.uk

\begin{abstract}
A new approach for biaxial loading of fibre reinforced composites is presented, based on the use of a Modified Arcan Fixture (MAF). In addition to combined tension-shear loading which can be achieved using a conventional Arcan fixture, the MAF allows the application of pure compression and compression-shear loading. Digital Image Correlation is used to obtain the full-field deformations of the specimens to establish the load response and failure behaviour for a range of multiaxial stress-strain states. The approach is demonstrated on glass/epoxy prepreg laminates. For unidirectional matrix dominated laminate it is shown that the failure envelope is described accurately by Puck’s inter-fibre failure theory. For the multidirectional matrix-dominated laminate it is shown that the in-situ strength is much greater than that predicted using the unidirectional properties. The potential of the MAF for characterisation over the entire combined tension-shear and compression-shear domains using a single fixture is demonstrated.
\end{abstract}

Keywords: Polymer-matrix composites (PMCs); biaxial strength; biaxial mechanical testing; modified Arcan fixture

\subsection{Introduction}

There is an increasing requirement to understand better the behaviour of composite materials subject to complex multi-axial loading conditions as to enable efficient deployment in a range of load carrying applications in the aerospace, marine and other industries. The analysis of multidirectional composites subjected to multiaxial loading has progressed 
through initiatives such as the World Wide Failure Exercises (WWFE-1, 2 and 3) [1-3]. In order to replace costly and time-consuming physical materials and structures tests with model-based virtual testing, robust material and failure models must be established, validated by experimental data. Currently there is a scarcity of reliable experimental data for multiaxial load cases due to the complexity of multiaxial testing and design of the test specimens. In fact, a generally agreed consensus has not been reached in the composites community on the appropriate definition and design of multiaxial testing methodologies for composites.

Most biaxial or multiaxial tests reported in the WWFEs [1-3] were performed on filament-wound small diameter tubular specimens subjected to combined tension/compression, internal pressure and/or torsional loading. However, tubular specimens are not representative of typical laminated composite materials coupon specimens or structures which are flat/planar or display a large curvature radius compared with the laminate thickness, and where the arrangement of reinforcement fibres is ply-wise discretely discontinuous. For that reason, cruciform specimens often have been chosen [4-9] to characterise the biaxial mechanical performance of composite laminates for biaxial tensiontension, tension-compression and compression-compression loading. Successful testing of cruciform specimens requires extensive and careful machining of the specimens to create a reduced gauge section thickness and a corner fillet to prevent premature failure outside the gauge section. In addition, a sophisticated biaxial test machine with four independent actuators is often required. For the tension-shear load regime, the Arcan test rig [10-13], originally developed for shear testing of polymers and composites, can be modified by adding a sequence of loading holes in the arms of the fixture to achieve combinations of shear and tensile stress states. In particular, Tan et al. [13] examined the subcritical damage mode of quasi-isotropic central-notched and open-holed CFRP laminate subjected to combined tension and shear, and pure compression using a modified Arcan rig. However, the conventional Arcan rig is restricted to pure tension or combined tension-shear load cases and cannot be utilised for testing specimens loaded in the combined compression-shear load regime or in pure compression. Moreover, the stress state in a biaxially-loaded multidirectional laminated specimen is complex, and due to its irregular geometry and anisotropic nature can only be modelled realistically using e.g. non-linear finite element analysis or other advanced numerical tools. Thus, to advance the understanding of the biaxial load response and failure behaviour of composite materials, a combined experimental and numerical approach is required. A prerequisite for enabling this is the development of a test 
rig or a standardised test, which can generate high fidelity multiaxial experimental data for validation of numerical models and failure theories.

Following the previous success of biaxial testing on polymer foam materials [14], the focus of the present paper is on the development and validation of a novel modified Arcan fixture (MAF) setup (Figure 1) for the investigation of the in-plane biaxial mechanical response and failure behaviour of multidirectional composite laminates. Three different Eglass/epoxy laminate configurations are investigated; two that display matrix dominated load response and failure behaviour with stacking sequences $[90]_{12}$ and $[+60 /-60]_{3 s}$, and another that displays distinctly fibre dominated response characteristics with stacking sequence [30/+30]3s. Figure 1 also shows the butterfly-shaped test specimen geometry used for this study; more details of the specimen design is given in Section 2.1. The MAF enables the application of combined tension/compression and shear loading states (i.e. pure tension, pure compression, pure shear, biaxial tension-shear and biaxial compression-shear) to the specimen through a series of loading holes every $15^{\circ}$ spanning an arc of $180^{\circ}$ on the loading arms (Figure 1); more details of the MAF geometry and design are provided in Section 2.1. In contrast to the standard Arcan rig, compression and compression-shear testing is facilitated by the introduction of a pair of anti-buckling guide rails fixed to the MAF arms on both sides, which serve to eliminate out-of-plane displacement of the rig. The desired normal to shear stress ratio is selected by using appropriate pairs of loading holes.

The mechanical response and failure of unidirectional [90] $]_{12}$ specimens is investigated and exploited to validate inter-fibre failure criteria, that are used as the basis for predicting failure in angle-ply laminates. The purpose of the work is to demonstrate the feasibility of the MAF approach and that accurate material properties can be obtained from complex loading in the shear-compression domain by using such a fixture. To enable a detailed evaluation of the effectiveness of the MAF approach, the specimens were imaged on both sides so that $2 \mathrm{D}$ Digital Image Correlation (DIC) could be used to obtain full-field measurement of in-plane strain, thereby identifying damage during loading, and also enabling the strains on both sides of the specimen to be obtained to assess if any out-of- plane bending was being induced. It is demonstrated that the rig has the potential to allow full characterisation of the composite laminate strength in the combined tension/compression-shear stress domain using a single test fixture and hence obtaining the corresponding failure envelope, which is not possible with the conventional Arcan rig. 


\subsection{Methodology}

\subsection{Modified Arcan Fixture (MAF) and specimen fabrication}

The MAF consists of a pair of boomerang-shaped arms (with diameter about $0.47 \mathrm{~m}$ and thickness $40 \mathrm{~mm}$ ) made from high strength aluminium alloy Alumec 89. The specimen is secured in the centre of the fixture at both ends of the specimen by mechanical grips made from Uddeholm Impax Supreme steel via four M5 bolts tightened to $5 \mathrm{Nm}$ of torque (the recommended maximum value). The bolts served to align the specimen in the grips and to provide mechanical clamping forces such that the specimen could be primarily loaded by friction between the grips, which have knurled surfaces to enhance the friction. The MAF is designed so that it can be attached to a standard universal test machine via two double-sided fork-lugs, where all combinations of tension/compression and shear loading are achieved with a positive applied displacement.

The butterfly configuration was chosen to encourage failure at a known position. The radius of the waisted part of the specimen clearly has the potential to act as a notch and encourage premature or unexpected failure. To examine this, specimens were initially machined with three different notch radii $10 \mathrm{~mm}, 5 \mathrm{~mm}$ and a sharp notch $(\sim 0.7 \mathrm{~mm}$ i.e. the smallest feasible radius that can be produced with the waterjet cutter used for the specimen manufacture). Similar to the results from the polymer foam material testing [14], preliminary tests showed that failure for most specimens tends to initiate at the site of stress concentration where the curvature of the notch meets the straight edge (Point ' $A$ ' in Figure 1). The largest notch radius, i.e. $10 \mathrm{~mm}$, gave the crack initiation location farthest away from the specimen waist and near to the tabs. However, it was decided not to use the sharp notch specimens as the diameter of the waterjet could not be controlled accurately during machining the sharpest radius, thus making it impossible to achieve a consistent notch radius. The butterfly specimen geometry with a notch radius of $5 \mathrm{~mm}$ gave the best compromise and was therefore selected for the tests, as this was deemed a sufficient compromise to demonstrate the MAF feasibility.

The specimen material considered was E-glass/RP528 UT300 E00 M32 prepreg system with a nominal ply thickness of $0.25 \mathrm{~mm}$. Identical panels with three different stacking sequences: $[90]_{12},[+60 /-60]_{3 s}$ and $[-30 /+30]_{3 s}$, were fabricated. The corresponding fibre direction $\theta$ with respect to the reference horizontal axis of the specimen is illustrated in Figure 1 . The three stacking sequences are representative of unidirectional, matrix-dominated angle-ply and fibre-dominated angle-ply laminates, respectively, with the main goal being to 
study the applicability of the MAF set-up for testing a broad range of multidirectional laminates. The laminates were cured at $120^{\circ} \mathrm{C}$ and 6.2 bar for an hour, as specified by the supplier, which resulted in a cured thickness of nominally $2.9 \mathrm{~mm}$. Cross-plied end tab strips made from the same composite material system of stacking sequence [+45/-45]2s which generally matches the stiffness of all tested laminates were attached using thin film adhesive (epoxy adhesive film SA80 from Gurit). The laminates were then cured under uniform pressure inside a vacuum bag to produce a minimal thickness and uniform bond layer with low void content before they were waterjet-cut to the final butterfly shape.

\subsection{Experimental setup and procedures}

The tests were performed using an Instron $100 \mathrm{kN} 5800$ servo-hydraulic universal test machine. After mounting the specimens in the fixture, the hydraulic actuator was set in displacement control mode and a small pre-tensile load of roughly $0.2 \mathrm{kN}$ was applied to take up the initial slack in the pin fittings of the rig. The specimens were then loaded at a rate of 1 $\mathrm{mm} / \mathrm{min}$ until first observable damage occurred, which in most cases also coincided with catastrophic failure of the specimens.

To enable the application of DIC, prior to testing a black speckle pattern on a white background was applied on the specimen surfaces with matt spray paints. The size of the speckles was mostly in the range of 5-10 pixels. The specimens were aligned carefully using the two columns of the test machine as a reference such that the specimens were aligned to be parallel to the camera sensor. Image acquisition was performed using two 5MP Imager E-Lite cameras with 8.5 bits of dynamic range paired with Sigma 105mm f2.8 EX DG Macro lenses at the spatial resolution of 45 pixels/mm which allowed the entire gauge section of the specimen to be imaged, while DIC was performed using the commercial software DaVis. The DIC images in the following section were post-processed with an interrogation subset size of 51 x 51 pixels with a step-size of 31 pixels. These DIC processing parameters were found to give the best trade-off between spatial resolution and measurement noise for this testing. The load signal from the load cell was fed into the DIC system as well as the Strainsmart data acquisition system which was used to extract the load-crosshead displacement data during testing. An overview of the experimental setup is shown in Figure 2.

The testing matrix is shown in Table 1 . Nine bidirectional load configurations were tested for the $[90]_{12}$ laminate; six for the $[+60 /-60]_{3 s}$ laminate; four for the $[-30 /+30]_{3 s}$ laminate. It should be noted that a second batch specimens with a waist width of $25 \mathrm{~mm}$ 
instead of $28.56 \mathrm{~mm}$ were tested for the pure tension $\left(\alpha=0^{\circ}\right)$ and pure compression $(\alpha=$ $\left.180^{\circ}\right)$ load cases of the $[+60 /-60]_{3 s}$ laminate. The difference in width should not pose a problem as the failure stress were simply normalised using the actual width and the nominal thickness of $2.9 \mathrm{~mm}$. Two preliminary unidirectional [0]12 specimens were also tested in the pure shear configuration $\left(\alpha=90^{\circ}\right)$, but are used only for comparative purposes and therefore are discussed briefly. The angle $\alpha$ refers to the angle between the loaded hole and the first hole of the loading arm $\left(\alpha=0^{\circ}\right)$ as shown in Figure 1. The load, $P$, applied by the test machine is related to the in-plane normal stress, $\sigma_{x x}$, and the shear stress, $\tau_{x y}$, acting at the specimen gauge section as follows:

$$
\begin{gathered}
\sigma_{x x}=\frac{P \cos \alpha}{w t} \\
\tau_{x y}=\frac{P \sin \alpha}{w t}
\end{gathered}
$$

where $w$ and $t$ are the width and thickness of the specimen. The global $\mathrm{x}$ and $\mathrm{y}$ axes with respect to the specimen are shown in Figure 1.

After failure, selected [+60/-60]3s and [-30/+30] $]_{3 s}$ specimens as indicated in Table 1 were CT scanned to investigate their failure modes in Nikon/Xtek $160 \mathrm{kVp}$ Benchtop. The images were reconstructed using the open image processing software ImageJ.

\subsection{Experimental results}

\section{$3.1[90]_{12}$ unidirectional specimens}

Most of the [90] $]_{12}$ butterfly specimens failed by inter-fibre matrix failure around the waist along a perpendicular, straight and flat fracture plane width of about 29-30 mm. The exceptions were for the combined compression-shear load cases, with $\alpha=135^{\circ}, 150^{\circ}$ and $165^{\circ}$, and the pure compression ( $\alpha=180^{\circ}$ ) where the fracture planes inclined at an oblique angle $\theta_{f p}$. Photographs of the failed test specimens for selected load cases are shown in Figure 3; in-plane views are shown in Figure 3(a)-(d). Side views of the three compression-shear ( $\alpha$ $=150^{\circ}$ ) specimens are shown in Figure 3(e). The width of each individual fracture plane was measured with a calliper, while $\theta_{f p}$ was estimated from images of the side view of the specimens as shown in Figure 3(e). It should be noted that for this special case of unidirectional [90 $]_{12}$ laminate, it is more convenient to adopt the material 1-2 axis instead of 
the global $x-y$ axis as shown in Figure 1 to describe the stresses, where 1-axis refers to the fibre direction, while 2-axis refers to the transverse direction, i.e. the 1 and 2 axes coincide with the $y$ and $x$ axes respectively. The average failure load for different load configurations as well as the corresponding average in-plane failure stresses ( $\sigma_{22}$ and $\tau_{21}$ on the material axis) and fracture plane angles $\theta_{f p}$ are summarised in Table 2 .

As all the fracture planes are well defined, it is straightforward to transform the inplane stresses (on the material axis) into effective normal and shear stresses ( $\sigma_{n}$ and $\tau_{\text {eff }}$ ) on the fibre parallel fracture plane [15]. Following the fundamental ideas on which the Puck inter-fibre failure (IFF) criterion are based [15, 16], it is hypothesised that the inter-fibre fracture is influenced by the three stresses $\sigma_{n}, \tau_{n t}$ and $\tau_{n l}$ only, i.e.:

$$
\begin{aligned}
\sigma_{n} & =\sigma_{22} \cos ^{2} \theta_{f p} \\
\tau_{n t} & =-\sigma_{22} \sin \theta_{f p} \cos \theta_{f p} \\
\tau_{n l} & =\tau_{21} \cos \theta_{f p} \\
\tau_{e f f} & =\sqrt{\tau_{n t}^{2}+\tau_{n l}^{2}}
\end{aligned}
$$

where the subscript $n$ refers to the direction normal to the fracture plane, $l$ refers to the longitudinal direction (fibre direction) parallel to the fracture plane and $t$ refers to the transverse direction parallel to the fracture plane.

To define the failure envelope in the normal-shear stress domain, both the in-plane stresses ( $\sigma_{22}$ and $\left.\tau_{21}\right)$ and the effective stresses on the fracture plane ( $\sigma_{n}$ and $\tau_{e f f}$ ) of individual specimens are plotted. Figure 4 gives the maximum principal strain $(\varepsilon I)$ and tensorial shear strain $\left(\varepsilon_{21}\right)$ maps obtained from the DIC for pure shear loading on a [90 $]_{12}$ specimen at the applied load of $3.94 \mathrm{kN}$, i.e. at the last frame before final failure. Figure 4 shows that the magnitude of both $\varepsilon_{I}$ and $\varepsilon_{21}$ are about the same at the gauge section confirming that a pure shear stress state has been achieved. The $\varepsilon 21$ values were extracted along the waist of the UD [90 $]_{12}$ specimens loaded in the pure shear $\left(\alpha=90^{\circ}\right)$ configuration and averaged to produce the average shear stress ( $\left.\tau_{21}\right)$-engineering shear strain curves $\left(\gamma_{21}\right)$ in Figure 5, plotted alongside with those given by the unidirectional [0]12 specimens from the preliminary test. The shear modulus, $G_{12}$, of the $[0]_{12}$ specimens matches the value given in the manufacturer's datasheet of $4.35 \mathrm{GPa}$. In general, the shear responses are highly non-linear. The initial shear modulus (determined as the slope of the stress-strain curve within a strain range of $0.15 \%$ $0.55 \%$ ) of the $[90]_{12}$ specimens was found to be $3.1 \mathrm{GPa}$, which is significantly lower than 
the $[0]_{12}$ specimens due to the lack of structural support from the fibres. Therefore, only a small portion of the shear stress-strain curve was generated before final failure. Similarly, the shear strength of the [90 $]_{12}$ specimens is also markedly lower than that of the $[0]_{12}$ specimens which is about $70 \mathrm{MPa}$ (also in agreement with the reported datasheet value of $72 \mathrm{MPa}$ ). The results indicate that the shear response of a [90] laminate is matrix-dominated, whereas a [0] laminate is fibre-dominated, and they are not equivalent although they are both determined from tests conducted on unidirectional laminates.

Average shear stress $\left(\tau_{21}\right)$ is plotted against average engineering shear strain $\left(\gamma_{21}\right)$ in Figure 6 for the [90 $]_{12}$ laminate, which shows the influence of transverse normal stress $\left(\sigma_{22}\right)$ at different normal-to-shear stress $\left(\sigma_{22} / \tau_{21}\right)$ ratios. It can be observed that the initial slope of the curves, i.e. the apparent or effective shear modulus, does not change significantly with transverse normal stress. However, the point where the stress-strain relationship starts to deviate from linearity, the proportionality or 'yield' limit, is suppressed or delayed as the transverse normal stress becomes increasingly compressive up to the loading angle $\alpha=135^{\circ}$ $\left(\sigma_{22} / \tau_{21}=-1\right)$, beyond which the proportionality limit point starts to drop again. This shows that the presence of compressive stress retards the development and coalescence of microdamage, causing the nonlinear behaviour and allowing the specimen to fail at higher stresses and strains. It should be noted that at high compression $\left(\sigma_{22} / \tau_{21}<-1\right)$ out-of-plane buckling of the specimens became significant, the speckle coating started to peel off, and the DIC no longer gave accurate in-plane strain values. In these cases, the response was dominated by the transverse compression such that yielding occurred at an inclined angle and the complete inplane shear stress-strain response could not develop and be observed. Nonetheless, a suitable composite material constitutive model would be able to predict or capture this pressure (hydrostatic stress) dependent behaviour. This is beyond the scope of this paper, however, and will not be discussed further. The results demonstrate that the MAF rig can be utilised to produce experimental data for validation and verification purposes of material models and failure theories. Selected key material properties measured from the tests are tabulated in Table 3.

\section{$3.2[+60 /-60]_{3 s}$ angle-ply specimens}

Photographs of the failed [+60/-60 $]_{3 s}$ specimens tested under the various load configurations are shown in Figure 7. Figures 7(a)-(f) show the in-plane view and provide an indication of the failure mode. Figures 7(g)-(i) show the side view and the through thickness 
angle of failure for the specimens in Figure 7(d)-(f) respectively. The failure loads for each case are given in Table 4. In most cases failure was indicated by a sharp decrease in load, with some loading configurations showing stiffness reduction kinks in the load-displacement curves. In the pure tension loading, an extensive plateau in the curves was observed, signifying the event of fibre rotation after inter-fibre failure in both $+60^{\circ}$ and $-60^{\circ}$ plies before catastrophic failure. In the compression dominated loading, the load-displacement curves were mainly non-linear without any obvious kink.

In general, all specimens failed at the gauge area, but did not give a well-defined clean and flat fracture surface, which makes the definition of the fracture stresses on the fracture path/plane less straightforward than for the [90]12 specimens. However, it is reasonable to assume that the maximum normal and shear stresses occurred at the waist of the specimen, and accordingly the average stresses across the waist are used as the representative stresses in plotting the failure envelope in Section 4.2. The global average in-plane normal and shear stresses ( $\sigma_{x x}$ and $\tau_{x y}$ ) across the specimen waist at the failure initiation load are calculated using Equations (1) and (2), whose values are shown in Table 4 as well.

Macroscopic failure generally appeared to initiate from the stress concentration region where the notch curvature meets the straight edge, then propagating along the $-60^{\circ}$ direction to the tab region (Figure 7). Fibre fracture and fibre kinking occurred in the $+60^{\circ}$ surface ply following the direction of the IFF in the adjacent $-60^{\circ}$ plies leading to catastrophic failure (see the CT images in Figure 8). Stress-whitening on the surface plies due to the IFF in the adjacent $-60^{\circ}$ plies can be seen in Figure 7 as well. However, for specimens subjected to pure shear loading (Figure 7(c)), the crack morphology was unexpectedly different, i.e. it started from the straight edge and propagated to the tab on the other side. For combined compression-shear loading (Figure 7(d) and (e)), the crack initiated at/near the waist, with the macroscopic cracks running along the $-60^{\circ}$ direction, forming a pair of skew-symmetric wedge-shaped fracture planes inclined at an angle between $37^{\circ}-51^{\circ}$ on both sides of the specimens (Figure 7(g) and (h)). In the case of pure compression (Figure 7(f)), the two macroscopic cracks initiated near the waist, then propagated along the $+/-60^{\circ}$ direction and intersected in the middle, giving an inclined fracture plane at $51^{\circ}-54^{\circ}$ (Figure $7(\mathrm{i})$ ).

Figure 9 shows the maximum principal strain ( $\varepsilon I$ ) maps captured by DIC for the combined tension-shear $\left(\alpha=45^{\circ}\right)$ and pure shear $\left(\alpha=90^{\circ}\right)$ load configurations at the last frame before catastrophic failure occurred. There are streaks (in yellow in Figure 9) running 
in the $+60^{\circ}$ direction which are presumed to be subcritical micro-IFF in the matrix on the $+60^{\circ}$ surface ply before catastrophic failure, although the damage could not be physically observed in the failed specimens. High strain concentrations (associated with high stress concentration) can be observed near the end of the notch curvature. The high strain concentration at the top left corner of the principal strain map for the case of pure shear $(\alpha=$ $90^{\circ}$ ) is responsible for initiating the failure seen in Figure 7(c). The 2D DIC strain maps acquired for the compression dominated load cases $\left(\alpha=120^{\circ}, 150^{\circ}\right.$ and $\left.180^{\circ}\right)$ were not very informative nor reliable as the deformations and the failure mode were mainly out-of-plane.

\section{$3.3[-30 /+30]_{3 s}$ angle-ply specimens}

The response of the $[-30 /+30]_{3 s}$ specimens is fibre-dominated with respect to the loading direction. For loading angles $\alpha=45^{\circ}, 90^{\circ}$ and $120^{\circ}$, shear-out and bearing failure initiated prematurely at the pin holes of the specimens well before failure at the gauge section due to the high stiffness and strength of the laminate. This was followed by debonding of the end tabs. The tests were stopped when the pin hole failure occurred as it was not possible to load the specimen any further, so they are not discussed here. However, three specimens were successfully tested for the combined compression-shear $\left(\alpha=150^{\circ}\right)$ load case, one of them shown in Figure 10(a), with failure initiated at the average load of $19.03 \mathrm{kN}$ (c.v. 1.94\%) and failed catastrophically at $23.38 \mathrm{kN}$ (c.v. 3.00\%) due to out-of-plane buckling instability at the gauge section as shown in Figure 10(d). Multiple crack paths, including fibre fracture and a fibre kink band, can be observed. The fibre kink band in the $-30^{\circ}$ plies (Figure 10(b)) appears to run along the IFF crack of the adjacent $+30^{\circ}$ plies (Figure $10(\mathrm{c})$ ).

The observed behaviour for the $[-30 /+30]_{3 s}$ specimens poses the question regarding the feasibility of using the MAF and butterfly-shaped specimens for testing laminate configurations that display fibre-dominated behaviour, as well as for stronger carbon fibre reinforced laminates. To obtain failure in the gauge section, it will be necessary to achieve sufficiently high stresses to break the fibres. The butterfly specimen used for this study was designed to be loaded primarily by friction between the grips. The pin holes were intended for assisting alignment of the specimens during mounting in the test rig. However, the observed failure at the pin holes indicates that the frictional forces generated by the clamps were insufficient to stop the slippage of the specimens. Thus, to enable testing of laminate configurations with fibre dominated response characteristics, a re-design of the rig and specimen geometry is required; this will be addressed in future work. 


\subsection{Failure criteria}

\section{$4.1[90]_{12}$ unidirectional specimens}

The [90 $]_{12}$ specimens in all cases experienced inter-fibre failure giving a well-defined fracture plane parallel to the fibre direction near the waisted gauge section. To define the failure envelope, the material-axis in-plane stresses ( $\sigma_{22}$ and $\left.\tau_{21}\right)$ for all specimens are plotted in the $\sigma-\tau$ stress domain for the different loading configurations in Figure 11.

One of the best performing failure criteria according to the World Wide Failure Exercise (WWFE) is Puck's failure theory $[15,16]$. The predictive capability of the Puck failure theory was investigated for the tested [90 $]_{12}$ laminate configuration. Puck's failure theory is referred to as being 'physically based', i.e. it distinguishes between fibre failure and IFF modes. Based on considerations of the Mohr-Coulomb failure theory, Puck's IFF theory assumes that IFF is a brittle fracture, meaning that a sudden separation of material without pronounced deformations occurs in the fracturing area. This is relevant to the $[90]_{12}$ specimens. According to the theory $[15,16]$, IFF (as a function of in-plane $\sigma_{22}$ and $\tau_{21}$ ) is predicted if:

IFF Mode A:

$\sigma_{22} \geq 0$

$$
\sqrt{\left(\frac{\tau_{21}}{S_{21}}\right)^{2}+\left(1-p_{\perp \|}^{(+)} \frac{Y_{T}}{S_{21}}\right)^{2}\left(\frac{\sigma_{22}}{Y_{T}}\right)^{2}}+p_{\perp \|}^{(+)} \frac{\sigma_{22}}{S_{21}} \geq 1
$$

IFF Mode B:

$\sigma_{22}<0$ and
$0 \leq\left|\frac{\sigma_{22}}{\tau_{21}}\right| \leq \frac{R_{\perp \perp}^{A}}{\left|\tau_{21 c}\right|}$

$$
\frac{1}{S_{21}}\left(\sqrt{\tau_{21}^{2}+\left(p_{\perp \|}^{(-)} \sigma_{22}\right)^{2}}+p_{\perp \|}^{(-)} \sigma_{22}\right) \geq 1
$$

IFF Mode C:

$$
\begin{aligned}
& \sigma_{22}<0 \text { and } \\
& 0 \leq\left|\frac{\tau_{21}}{\sigma_{22}}\right| \leq \frac{\left|\tau_{21 c}\right|}{R_{\perp \perp}^{A}} \quad\left[\left(\frac{\tau_{21}}{2\left(1+p_{\perp \perp}^{(-)}\right) S_{21}}\right)^{2}+\left(\frac{\sigma_{22}}{Y_{C}}\right)^{2}\right] \frac{Y_{C}}{-\sigma_{22}} \geq 1
\end{aligned}
$$

where

$$
\begin{aligned}
& R_{\perp \perp}^{A}=\frac{Y_{C}}{2\left(1+p_{\perp \|}^{(-)}\right)}=\frac{S_{21}}{2 p_{\perp \|}^{(-)}}\left(\sqrt{1+2 p_{\perp \|}^{(-)} \frac{Y_{C}}{S_{21}}}-1\right) ; \\
& p_{\perp \|}^{(+)}=-\left(\frac{d \tau_{21}}{d \sigma_{22}}\right)_{\sigma_{22}=0} \text { of }\left(\sigma_{22}, \tau_{21}\right) \text { curve, } \sigma_{22} \geq 0 ;
\end{aligned}
$$


$p_{\perp \|}^{(-)}=-\left(\frac{d \tau_{21}}{d \sigma_{22}}\right)_{\sigma_{22}=0}$ of $\left(\sigma_{22}, \tau_{21}\right)$ curve, $\sigma_{22} \leq 0$;

$p_{\perp \perp}^{(-)}=p_{\perp \|}^{(-)} \frac{R_{\perp \perp}^{A}}{S_{21}} ;$

and $\tau_{21 c}=S_{21} \sqrt{1+2 p_{\perp \perp}^{(-)}}$, which is the shear stress at the intersection between modes B and C. The recommended values of parameters $p_{\perp \|}^{(-)}=0.25$ and $p_{\perp \perp}^{(-)}=0.30$ used in the WWFE $[15,16]$ for glass fibre reinforced composites are adopted here. The remaining strength values for E-glass/RP528 can be found in Table 3. Note that $S_{21}=S_{12}^{90^{\circ}}$ for a [90 $]_{12}$ laminate. In IFF Mode A, both tensile $\sigma_{22}$ and/or $\tau_{21}$ are predicted to cause fracture, giving $\theta_{f p}=0^{\circ}$. In IFF Mode B, it is predicted that the compressive $\sigma_{22}$ impedes fracture and that $\tau_{21}$ at fracture increases parabolically with increasing compressive $\sigma_{22}$ with a fracture angle $\theta_{f p}=0^{\circ}$. Finally, for IFF Mode C, it is predicted that the interaction between the dominant compressive $\sigma_{22}$ and $\tau_{21}$ on the stress action plane of the highest risk of fracture causes a fracture angle $\theta_{f p}=\cos ^{-1}\left(\sqrt{\frac{R_{\perp \perp}^{A}}{-\sigma_{22}}}\right)$.

The predictions according to Puck’s IFF theory is superimposed in Figure 11. It is observed that an excellent agreement between the predictions of the theory and the experimental data has been achieved. From Table 5, it is also observed that the agreement between the theoretical predictions and the experimental observations for $\theta_{f p}$ corresponding to IFF Mode C improves at higher transverse compression-shear ratios.

The transformed effective normal and shear stresses ( $\sigma_{n}$ and $\left.\tau_{e f f}\right)$ on the fracture plane parallel to the fibres are plotted in the $\sigma$ - $\tau$ stress domain in Figure 12 for all specimens. It is clear that the inter-fibre effective shear strength increases with increasing normal compressive stress. It is a generally accepted observation that the yield stress of polymeric materials depends on the hydrostatic pressure [17]. To further describe this behaviour, the Drucker-Prager failure criterion has been adapted to estimate the IFF fracture stresses. The Drucker-Prager failure criterion is a three-dimensional failure model which displays dependency of the hydrostatic stress components, and it is commonly used to describe the stress state at which granular geo-materials and porous materials reach their ultimate strength [18]. It can be expressed as: 


$$
\sqrt{J_{2}}=a+b I_{1}
$$

where $I_{1}$ is the first invariant of the Cauchy stress and $J_{2}$ is the second invariant of the deviatoric part of the Cauchy stress. The coefficients $a$ and $b$ are material constants which can be determined from two independent mechanical tests. For the 2D stress state induced in the [90 $]_{12}$ specimens, Equation (5) can be written in the following form (see derivation in Appendix):

$$
\left(\frac{\tau_{21}}{S_{21}}\right)^{2}=1+\left(\sqrt{\frac{4}{3}} \frac{1}{S_{21}}-\frac{2}{Y_{T}}\right) \sigma_{22}+\left(\frac{1}{Y_{T}^{2}}-\sqrt{\frac{4}{3}} \frac{1}{Y_{T} S_{21}}\right) \sigma_{22}^{2}
$$

Equation (6) is superimposed on the experimental data in Figure 12, and the agreement with the experimental observations is excellent, thus confirming that IFF failure is dependent on the hydrostatic stress state and well captured by the Drucker-Prager model.

The effect of transverse compression on the interlaminar shear failure strength is included in the Puck failure theory (IFF Mode B) and is defined through the slope/inclination parameter $p_{\perp \|}^{(-)}$. The tests conducted on [90]12 specimens using the MAF can provide a methodology to measure $p_{\perp \|}^{(-)}$directly. Using a linear fit of the data in Figure 12, a linear $p_{\perp \|}^{(-)}$ is found to be 0.304 . It suggests that the values $p_{\perp \|}^{(-)}=0.25$ and $p_{\perp \perp}^{(-)}=0.30$ as recommended by Puck $[16,17]$ are of the right order of magnitude. Moreover, the obtained value is not significantly different from the value measured for carbon/epoxy composites $\left(p_{\perp \|}^{(-)}=0.27\right.$ 0.34) using a symmetric double notch specimen [19].

After appropriate modification to account for the stress state in the tested specimens, the recently proposed Northwestern University's (NU) theory [20, 21] can be rewritten as follows:

$$
\tau_{21}=S_{12}^{90^{\circ}} \sqrt{1-\frac{2 G_{12}^{90^{\circ}}}{E_{2}^{T} S_{12}^{90^{\circ}}} \sigma_{22}}
$$

The NU theory also predicts similar shear strength enhancement in agreement with the experimental data as shown in Figures 11 and 12 for comparison. The theory was originally developed to predict interlaminar shear dominated failure in textile composites, but can be slightly amended to predict in-plane shear dominated failure as they are both inter-fibre 
failure (IFF) modes. Note that the NU theory is described purely by the mechanical properties presented in Table 3, i.e. without the need for the slope parameters.

\section{$4.2[+60 /-60]_{3 s}$ angle-ply specimens}

The average global in-plane normal and shear stresses ( $\sigma_{x x}$ and $\left.\tau_{x y}\right)$ at failure initiation acting across the waist of the [+60/-60] 3 s angle-ply specimens are plotted in Figure 13. Since they all failed predominantly by IFF, it is justified to use Puck’s IFF theory (Equation (4)) previously validated by the experimental data for the unidirectional [90 $]_{12}$ laminate, together with the linear elastic Classical Laminate Theory (CLT), to directly predict the first-ply IFF. The prediction is shown by the solid amber line in Figure 13. It is seen that this approach severely under-predicts the failure stresses by about $50 \%$ of the actual failure load. The failure trend is well captured, but it is clear that using Puck's IFF theory with values for UD laminates produces overly conservative results.

A way of reducing the conservatism would be to scale-up the failure envelope to match the experimental data by establishing the failure criterion as a function of the 'in-situ' strengths. The in-situ effect [22] is characterised by higher strengths of an individual ply in a multidirectional laminate when it is constrained by neighbouring plies with different fibre orientations in a laminate, compared with the strengths of the same ply in a UD laminate. The constrained layer effect, i.e. the in-situ strengths, depends on the thicknesses of the plies clustered together and on the fibre orientation of the constraining plies [22]. As there is insufficient in-situ experimental data for the failure behaviour of the [+60/-60]3s angle-ply specimens, it was necessary to estimate the in-situ strength values by obtaining a good fit to the experimental data shown in Figure 13. The estimated in-situ strengths, which are tabulated in Table 6, are below the values of a similar composite system E-glass/MY750 reported in [23], indicating that these are plausible values. The results highlighted that it is possible to use Puck's IFF theory with the in-situ strength values to predict the failure in a matrix-dominated angle-ply laminate.

For the case of combined compression-shear $\left(\alpha=120^{\circ}\right)$, Puck's IFF theory predicts that the first-ply failure corresponds to Mode B. Since Mode B is associated with closed cracks, it is possible for the laminate to continue to carry load and a change from IFF Mode B to Mode C [15], in which case an oblique fracture plane is expected. This could explain the appearance of a macroscopic oblique fracture plane in the specimens as shown in Figure 7(d). For the case of combined compression-shear at $\alpha=150^{\circ}$ and pure compression at $\alpha=180^{\circ}$, 
Mode C failure is predicted and therefore the oblique fracture plane observed in the specimens (Figure 7(e) and (f)) was expected.

\section{$4.3[-30 /+30]_{3 s}$ angle-ply specimens}

Only the specimens loaded by combined compression-shear $\left(\alpha=150^{\circ}\right)$ were successfully tested, i.e. failure occurred at the gauge section without premature pin-hole shear-out failure. They failed by a combination of IFF, fibre kinking and fracture, followed by out-of-plane instability (Figure 10). Using the same in-situ strengths as in Table 6, Puck's IFF theory predicts that first-ply failure (IFF Mode B) occurs in the $+30^{\circ}$ plies at a load of $20.83 \mathrm{kN}$, compared to the average experimental failure initiation load $19.03 \mathrm{kN}$ with an error of $5.8 \%$. The IFF in the $+30^{\circ}$ plies is evident in Figure 10 (c). No firm conclusions can be drawn from this comparison, as there is only one load case and the actual sequence of failure events leading to failure are complex.

\subsection{Conclusion}

The design of a biaxial test and the associated specimen for composite material testing is complicated and tedious. In this paper, a modified Arcan fixture (MAF) has been employed to investigate the biaxial strength of multidirectional E-glass/epoxy laminates. The MAF enables the application of pure compression or high compression to shear biaxial load conditions not possible using the conventional Arcan fixtures, in additional to pure tension and tension-shear loading. Successful testing of butterfly specimens of stacking sequences $[90]_{12}$ and $[+60 /-60]_{3 s}$, where the behaviour is matrix dominated, demonstrated that it is possible to establish an approach for composite testing where a complete biaxial failure envelope can be generated using a single test fixture and a single specimen geometry. 2D DIC was used to obtain strain fields on both sides of the specimens, which allows acquisition of valuable biaxial experimental data, such as strengths and elastic moduli, shear stress-strain constitutive response, shear strength enhancement slope parameters $p_{\perp \|}^{(-)}$, etc., which can be used to develop and validate numerical material models.

However, for the tests conducted on fibre-dominated specimens of stacking sequence $[-30 /+30]_{3 s}$ it was found that failure in all but one loading configuration occurred due to premature pin hole shear-out failure. The cause of the problem lies in the detailed design of the specimen grips used for the MAF, and further research is ongoing so that both fibre and 
matrix dominated laminate configurations can be tested throughout the tension-shear and compression-shear loading envelopes. Finally, the test campaign conducted has shown that the use of stereo DIC is necessary for compression-dominated load states, as the failure modes for such configurations display out-of-plane specimen deformations despite the fact that the MAF is stabilised with guide rails for compression loading.

Failure envelopes for the $[90]_{12}$ and $[+60 /-60]_{3 s}$ matrix dominated laminate configurations have been generated using the MAF in the $\sigma$ - $\tau$ stress space. It has been demonstrated that Puck's IFF theory is able to predict failure in excellent agreement with the experimental data for the UD [90 $]_{12}$ laminate, while modified in-situ strengths need to be used with the theory to predict failure of the multidirectional [+60/-60]3s.laminate. Further, it has been shown that the effective failure stresses on the fracture plane of the [90 $]_{12}$ laminate were well described by the Drucker-Prager failure model that includes the influence of hydrostatic stresses of the failure process, thus indicating that the hydrostatic pressure is important when predicting IFF. This also implies that the Drucker-Prager yield criterion is a promising candidate model to define yielding and progressive damage response in composite materials. Future work includes the development of a non-linear material model using biaxial experimental data obtained from the MAF, as well as redesign of the grips of the MAF and the geometry of the specimens so that fibre-dominated laminate configurations can be successfully tested.

\section{Acknowledgement}

The authors acknowledge the Department of Mechanical and Manufacturing Engineering of Aalborg University Denmark for manufacturing the MAF rig and $\mu$-VIS X-Ray Imaging Centre of University of Southampton (UoS) for providing the computed tomography facilities used in this study. The commission of the MAF rig was supported by the Research Institute for Industry of the Faculty of Engineering and the Environment at UoS and the Fundamental Research Grant Scheme (FRGS/1/2015/TK09/USMC/03/1) of the Ministry of Higher Education of Malaysia.

\section{References}

1. Hinton MJ, Kaddour AS, Soden PD. Failure criteria in fibre reinforced polymer composites: the World-Wide Failure Exercise. Elsevier 2004. 
2. Hinton MJ, Kaddour AS. The background to the Second World-Wide Failure Exercise. Journal of Composite Materials 2012; 46(19-20): 2283-2294.

3. Kaddour AS, Hinton MJ, Smith PA, Li S. The background to the Third World-Wide Failure Exercise. Journal of Composite Materials 2013; 47(20-21): 2417-2426.

4. Kureemun U, Ridha M, Tay TE. Biaxial tensile-compressive loading of unnotched and open-hole carbon epoxy crossply laminates. Journal of Composite Materials 2015; 49(23): 1-21.

5. Smits A, Van Hemelrijck D, Philippidis TP, Cardon A. Design of a cruciform specimen for biaxial testing of fibre reinforced composite laminates. Composites Science and Technology 2006; 66(7-8): 964-975.

6. Gower MRL and Shaw RM. Towards a planar cruciform specimen for biaxial characterisation of polymer matrix composites. Applied Mechanics and Materials 2010; 24-25: 115-120.

7. Welsh JS and Adams DF. An experimental investigation of the biaxial strength of IM6/3501-6 carbon/epoxy crossply laminates using cruciform specimens. Composites Part A: Applied Science and Manufacturing 2002; 33(6): 829-839.

8. Welsh JS, Mayes JS and Biskner AC. 2-D biaxial testing and failure predictions of IM7/977-2 carbon/epoxy quasiisotropic laminates. Composite Structures 2006; 75(1-4): 60-66.

9. Makris A, Ramault C, Van Hemelrijck D, Zarouchas D, Lamkanfi E, Paepegem WV. An investigation of the mechanical behavior of carbon epoxy cross ply cruciform specimens under biaxial loading. Polymer Composites 2010; 31(9): 1554-1561.

10. Voloshin A, Arcan M. Failure of unidirectional fiber-reinforced materials - new methodology and results. Experimental Mechanics 1980; 29(8): 280-284.

11. El-Hajjar R, Haj-Ali R. In-plane shear testing of thick-section pultruded FRP composites using a modified Arcan fixture. Composites Part B: Engineering 2004; 35(5): 421-428.

12. de Sousa Junior RR, Gouveia JR, Ito NM, dos Santos DJ. Failure prediction of hybrid composite using Arcan’s device and Drucker-Prager model. Polymer Testing 2017; 58: 256-261.

13. Tan JLY, Deshpande VS, Fleck NA. Failure mechanisms of a notched CFRP laminate under multi-axial loading. Composites Part A: Applied Science and Manufacturing 2015; 77: 56-66. 
14. Taher ST, Thomsen OT, Dulieu-Barton JM, Zhang S. Determination of mechanical properties of PVC foam using a modified Arcan fixture. Composites Part A: Applied Science and Manufacturing 2012; 43(10): 1698-1708.

15. Puck A, Schurmann H. Failure analysis of FRP laminates by means of physically based phenomenological models. Composites Science and Technology 1998; 58(7): 10451067.

16. Puck A, Schurmann H. Failure analysis of FRP laminates by means of physically based phenomenological models. Composites Science and technology 2002; 62(12-13): 16331662.

17. Sauer JA. Deformation, yield and fracture of polymers at high pressure. Polymer Engineering and Science 1977; 17(3): 150-164.

18. Alejano LR, Bobet A. Drucker-Prager Criterion. Rock Mechanics and Rock Engineering 2012; 45(6): 995-999.

19. Gan KW, Hallett SR, Wisnom MR. Measurement and modelling of interlaminar shear strength enhancement under moderate through-thickness compression. Composites Part A: Applied Science and Manufacturing 2013; 49: 18-25.

20. Daniel IM. Failure of composite materials. Strain 2007; 43(1): 4-12.

21. Daniel IM, Luo J-J, Schubel PM. Three-dimensional characterization of textile composites. Composites Part B: Engineering 2008; 39(1): 13-9.

22. Camanho PP, Davila CG, Pinho ST, Iannucci L, Robinson P. Prediction of in situ strengths and matrix cracking in composites under transverse tension and in-plane shear. Composites Part A: Applied Science and Manufacturing 2013; 37(2): 165-176.

23. Vyas GM, Pinho ST. Computational implementation of a novel constitutive model for multidirectional composites. Computational Materials Science 2012; 51(1): 217-224.

\section{Appendix}

The Drucker-Prager yield criterion [18] has the form:

$$
\sqrt{J_{2}}=a+b I_{1}
$$

where $I_{1}$ is the first invariant of the Cauchy stress, i.e.:

$$
I_{1}=\sigma_{11}+\sigma_{22}+\sigma_{33}
$$

and $J_{2}$ is the second invariant of the deviatoric part of the Cauchy stress: 


$$
J_{2}=\frac{1}{6}\left[\left(\sigma_{11}-\sigma_{22}\right)^{2}+\left(\sigma_{22}-\sigma_{33}\right)^{2}+\left(\sigma_{33}-\sigma_{11}\right)^{2}\right]+\tau_{12}^{2}+\tau_{23}^{2}+\tau_{13}^{2}
$$

and $a$ and $b$ are material constants determined from two independent mechanical tests.

Considering the material 1-2 axis stresses on the fracture plane parallel to the fibre direction of the [90]12 laminate loaded in the MAF, and assuming tranversely isotropic behaviour of the material (i.e the stress state $\sigma_{11}=\sigma_{33}=\tau_{23}=\tau_{13}=0$ ) is always true regardless of the inclination of the fracture plane), Equation (5) becomes:

$$
\sqrt{\frac{1}{3} \sigma_{22}^{2}+\tau_{21}^{2}}=a+b \sigma_{22}
$$

Uniaxial tensile and pure shear tests are chosen as the two independent mechanical tests to find $a$ and $b$. In a pure shear test, $\sigma_{22}=0$ and $\tau_{21}=S_{21}=S_{12}^{90^{\circ}}$. Therefore,

$$
a=S_{21}
$$

In a uniaxial tensile test, $\tau_{12}=0$ and $\sigma_{22}=Y_{T}$. Substituting these values in Equation (A3), the following quadratic equation needs to be solved with respect to $b$ :

$$
Y_{T}^{2} b^{2}+2 S_{21} Y_{T} b+S_{21}^{2}-\frac{1}{3} Y_{T}^{2}=0
$$

with the solution:

$$
b=\frac{-S_{21} \pm \sqrt{\frac{1}{3}} Y_{T}}{Y_{T}}
$$

Only the positive sign of the square root will give real-valued stresses. By substituting $a$ and $b$ in Equation (A3) and upon rearranging, the following is obtained:

$$
\left(\frac{\tau_{21}}{S_{21}}\right)^{2}=1+\left(\sqrt{\frac{4}{3}} \frac{1}{S_{21}}-\frac{2}{Y_{T}}\right) \sigma_{22}+\left(\frac{1}{Y_{T}^{2}}-\sqrt{\frac{4}{3}} \frac{1}{Y_{T} S_{21}}\right) \sigma_{22}^{2}
$$




\section{Figures and Captions}

Figure 1: The modified Arcan fixture (MAF) and the dimensions of the butterfly specimen.

Figure 2: Overview of the MAF experimental setup.

Figure 3: Failure of the [90 $]_{12}$ specimens under (a) combined tension-shear ( $\alpha=45^{\circ}$ ), (b) pure shear $\left(\alpha=90^{\circ}\right)$, (c) combined compression-shear $\left(\alpha=120^{\circ}\right)$ and (d) combined compression-shear $\left(\alpha=150^{\circ}\right)$ loading configurations. (e) The fracture plane of the specimen in (d) generally inclines at an angle about $53^{\circ}$.

Figure 4: Maximum principal strain, $\varepsilon$ (left) and tensorial shear strain, $\varepsilon 21$ (right) maps for the pure shear $\left(90^{\circ}\right)$ load configuration of the [90] $]_{12}$ specimens at applied load $3.94 \mathrm{kN}$.

Figure 5: The average shear stress-strain curve extracted using the DIC strain data for unidirectional [0]12 and [90 $]_{12}$ laminates.

Figure 6: The shear stress-strain curves of different $\sigma_{22} / \tau_{21}$ ratios for [90 $]_{12}$ laminate. The curves are offset for clarity.

Figure 7: Failure of the [+60/-60 $]_{3 \text { s }}$ specimens under (a) pure tension $\left(\alpha=0^{\circ}\right)$; (b) combined tension-shear $\left(\alpha=45^{\circ}\right)$; (c) pure shear $\left(\alpha=90^{\circ}\right)$; (d) combined compression-shear $\left(\alpha=120^{\circ}\right)$; (e) combined compression-shear $\left(\alpha=150^{\circ}\right)$; (f) pure compression $\left(\alpha=180^{\circ}\right)$ loading configurations. (g) to (i) give the respective side-view of the specimens in (d) to (f) showing fracture plane generally at an angle $\theta_{f p}$ between $37^{\circ}-54^{\circ}$.

Figure 8: Failure of the [+60/-60]3s specimens under (top row) combined tension-shear $(\alpha=$ $45^{\circ}$ ) and (bottom row) pure shear $\left(\alpha=90^{\circ}\right)$. CT images of the first two plies in both specimens showing fibre kinking and matrix failure.

Figure 9: Maximum principal strain, $\varepsilon_{I}$ maps for (left) the combined tension-shear $\left(\alpha=45^{\circ}\right)$ load configuration at $8.09 \mathrm{kN}$ loading, and (right) the pure shear $\left(\alpha=90^{\circ}\right)$ load configuration at $12.92 \mathrm{kN}$ loading.

Figure 10: (a) Failure of the $[-30 /+30]_{3 s}$ specimens under combined compression-shear $\left(150^{\circ}\right)$ showing complex crack pattern; (b) CT image of the $-30^{\circ}$ ply showing a fibre kink band along the matrix crack of the adjacent $+30^{\circ}$ ply; (c) CT image of the $+30^{\circ}$ ply showing multiple IFF cracks along the fibre direction; (d) CT images of the specimen along the section highlighted by the dotted line in (a) showing out-of-plane instability leading to catastrophic failure.

Figure 11: In-plane failure stresses of the [90 $]_{12}$ laminate in the $\sigma_{22}-\tau_{21}$ domain.

Figure 12: Effective failure stresses on the fracture plane of the [90] $]_{12}$ laminate in the $\sigma_{n}-\tau_{\text {eff }}$ domain.

Figure 13: In-plane stresses of the $[+60 /-60]_{3 s}$ laminate in the $\sigma_{x x}-\tau_{x y}$ domain. 


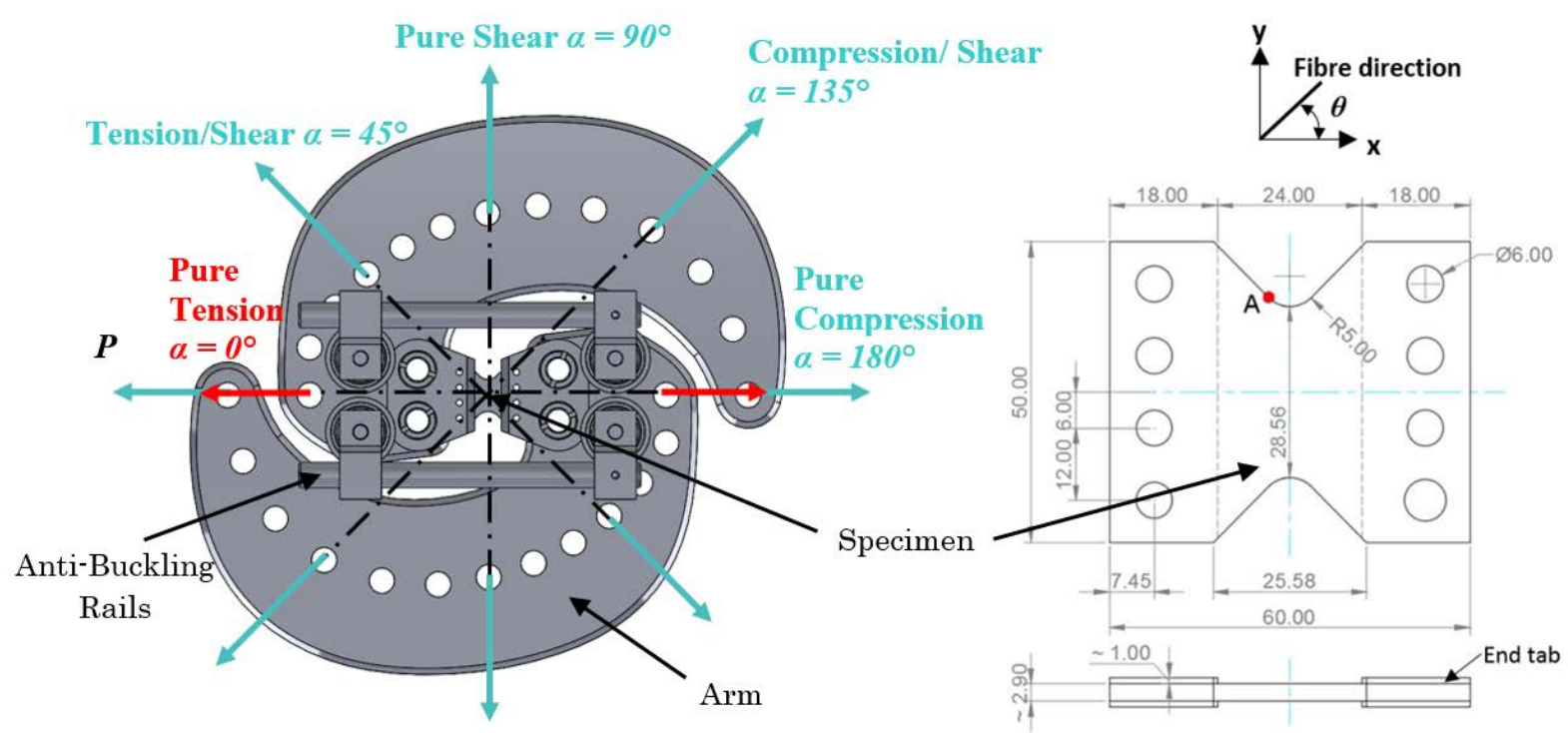

Figure 1: The modified Arcan fixture (MAF) and the dimensions of the butterfly specimen.

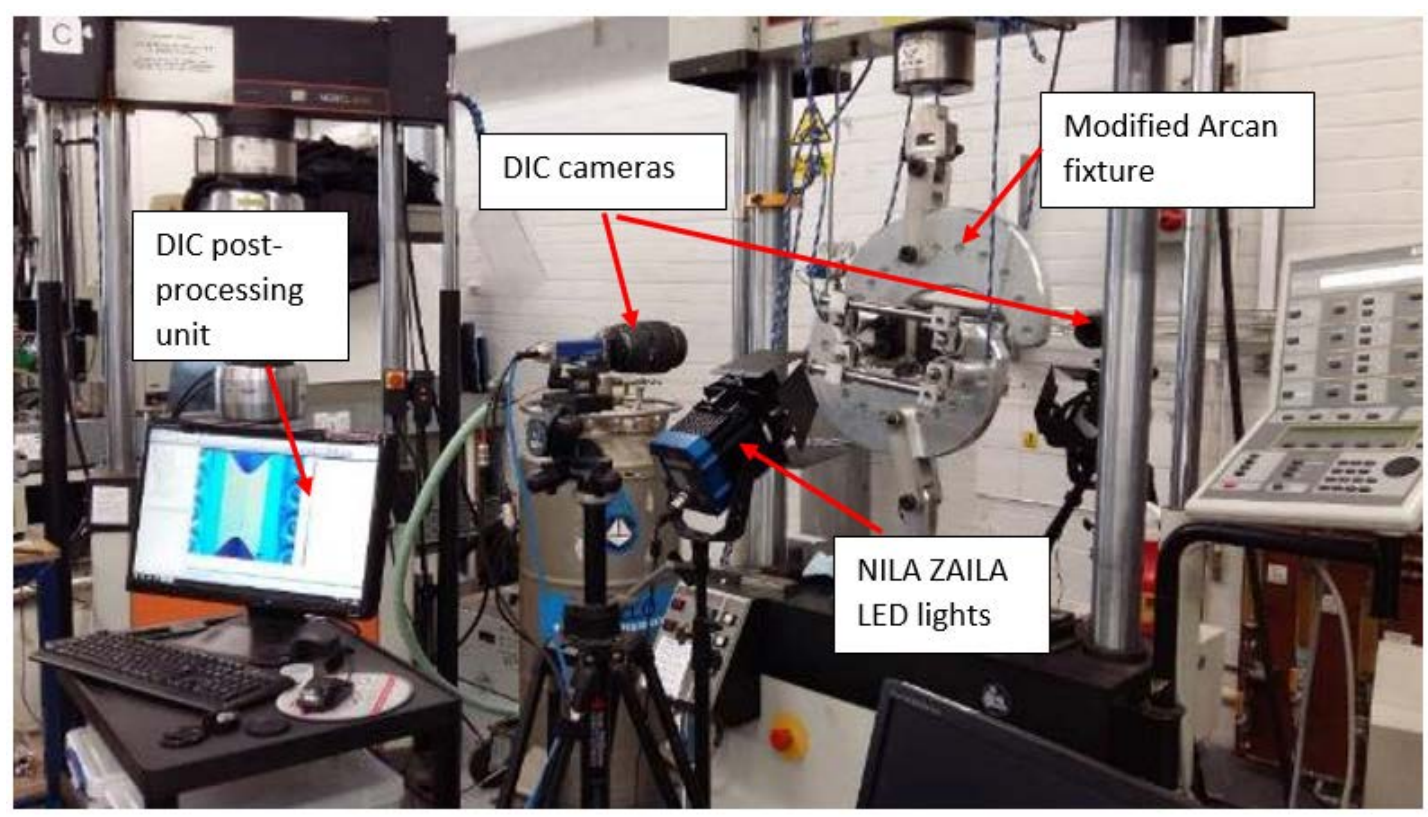

Figure 2: Overview of the MAF experimental setup. 

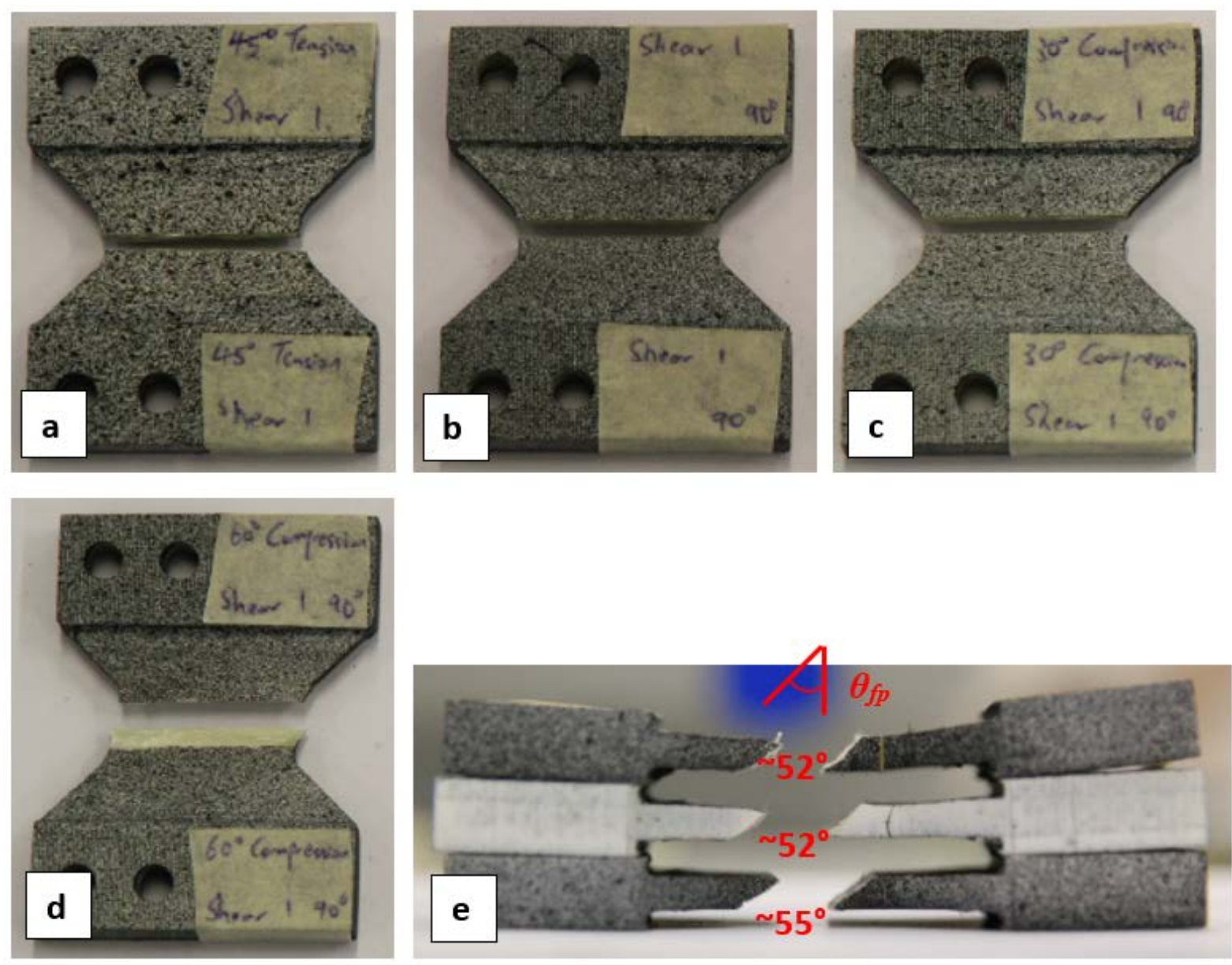

Figure 3: Failure of the [90 $]_{12}$ specimens under (a) combined tension-shear ( $\left.\alpha=45^{\circ}\right)$, (b) pure shear $\left(\alpha=90^{\circ}\right)$, (c) combined compression-shear $\left(\alpha=120^{\circ}\right)$ and (d) combined compression-shear $\left(\alpha=150^{\circ}\right)$ loading configurations. (e) The fracture plane of the specimen in (d) generally inclines at an angle about $53^{\circ}$.
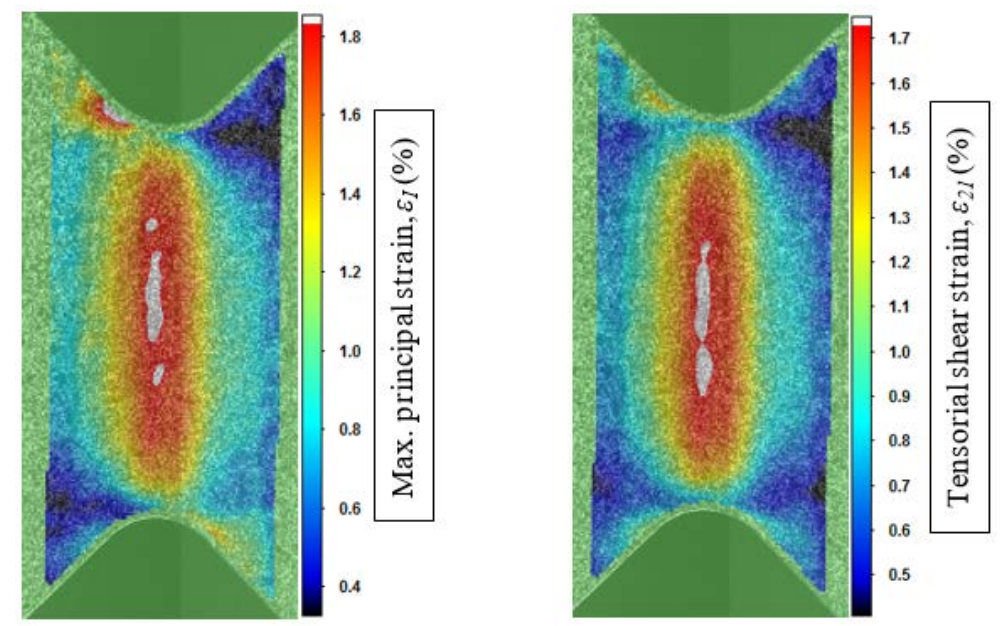

Figure 4: Maximum principal strain, $\varepsilon_{I}$ (left) and tensorial shear strain, $\varepsilon_{21}$ (right) maps for the pure shear $\left(90^{\circ}\right)$ load configuration of the [90] $]_{12}$ specimens at applied load $3.94 \mathrm{kN}$. 


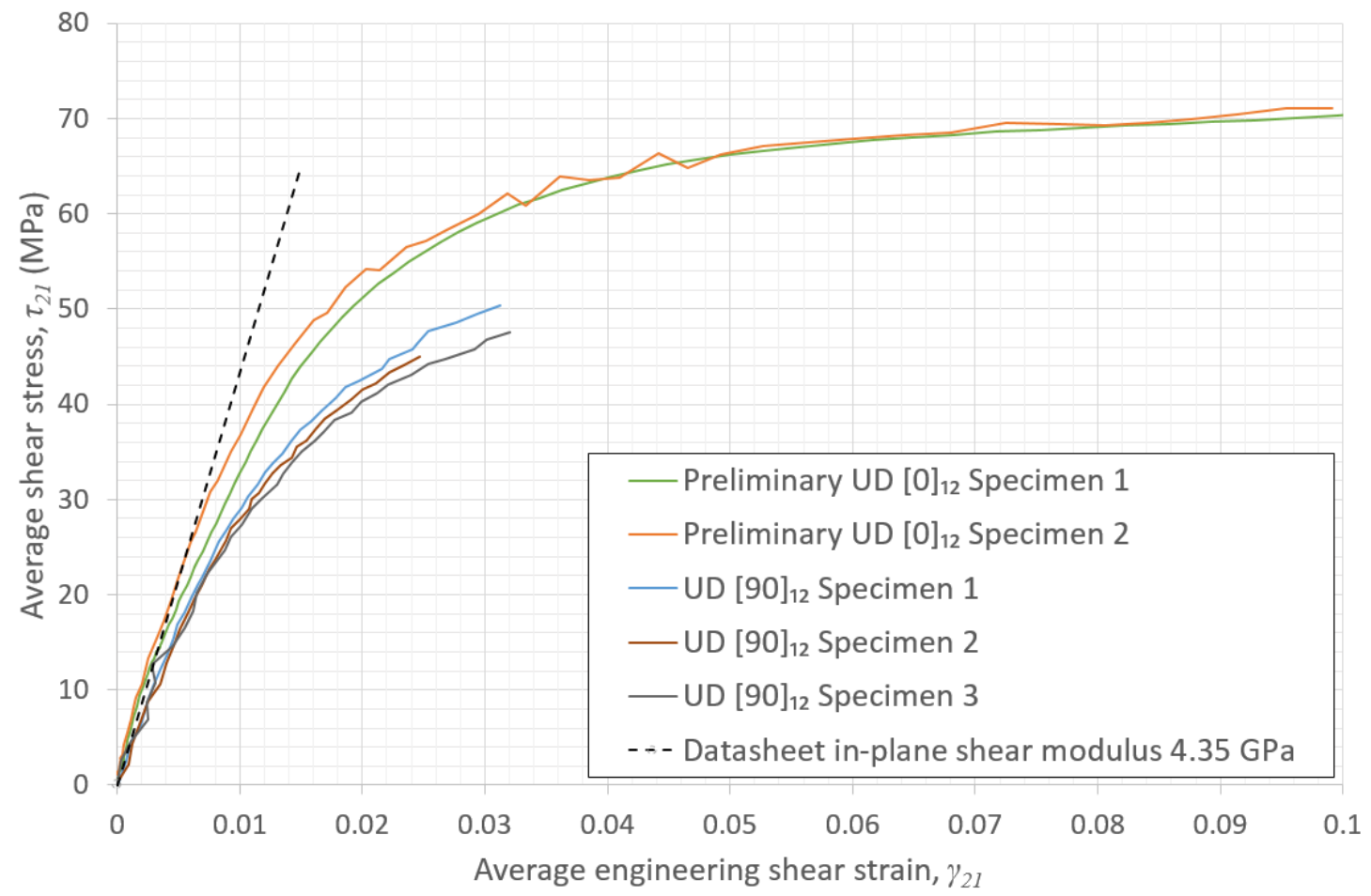

Figure 5: The average shear stress-strain curve extracted using the DIC strain data for unidirectional $[0]_{12}$ and $[90]_{12}$ laminates.

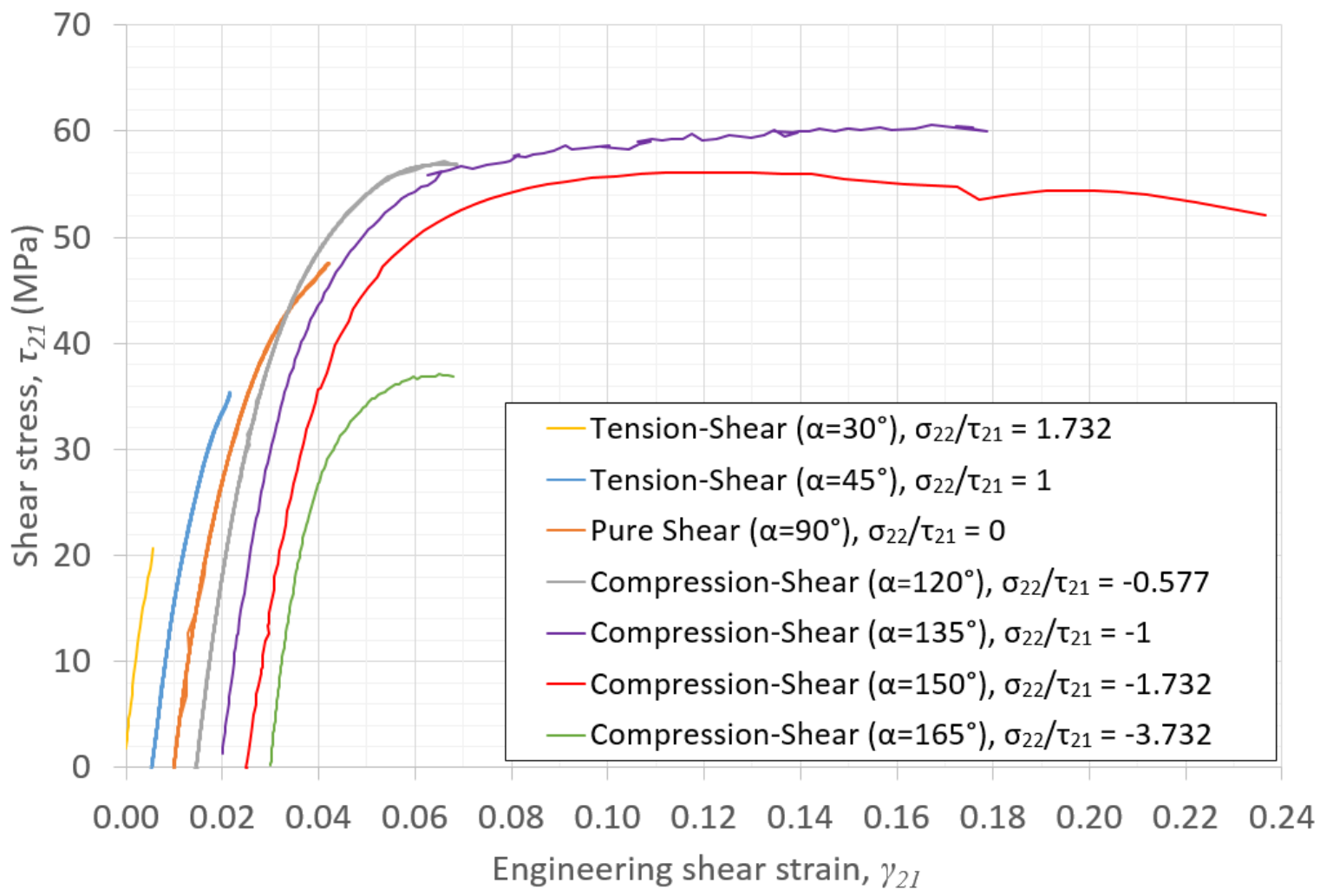

Figure 6: The shear stress-strain curves of different $\sigma_{22} / \tau_{21}$ ratios for [90 $]_{12}$ laminate. The curves are offset for clarity. 

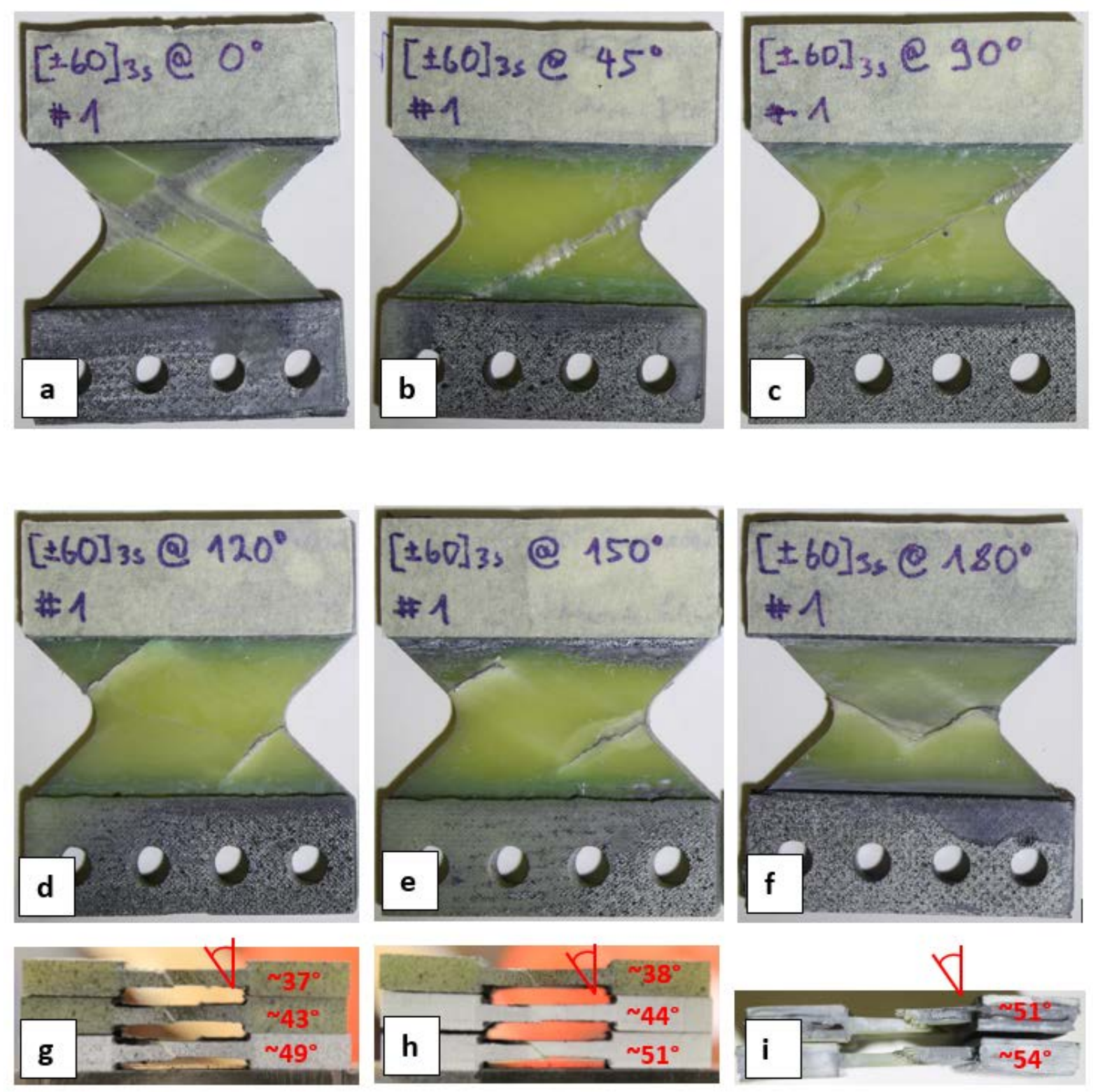

Figure 7: Failure of the [+60/-60 $]_{3 s}$ specimens under (a) pure tension $\left(\alpha=0^{\circ}\right)$; (b) combined tension-shear $\left(\alpha=45^{\circ}\right)$; (c) pure shear $\left(\alpha=90^{\circ}\right)$; (d) combined compression-shear $\left(\alpha=120^{\circ}\right)$;

(e) combined compression-shear $\left(\alpha=150^{\circ}\right)$; (f) pure compression $\left(\alpha=180^{\circ}\right)$ loading configurations. (g) to (i) give the respective side-view of the specimens in (d) to (f) showing fracture plane generally at an angle $\theta_{f p}$ between $37^{\circ}-54^{\circ}$. 

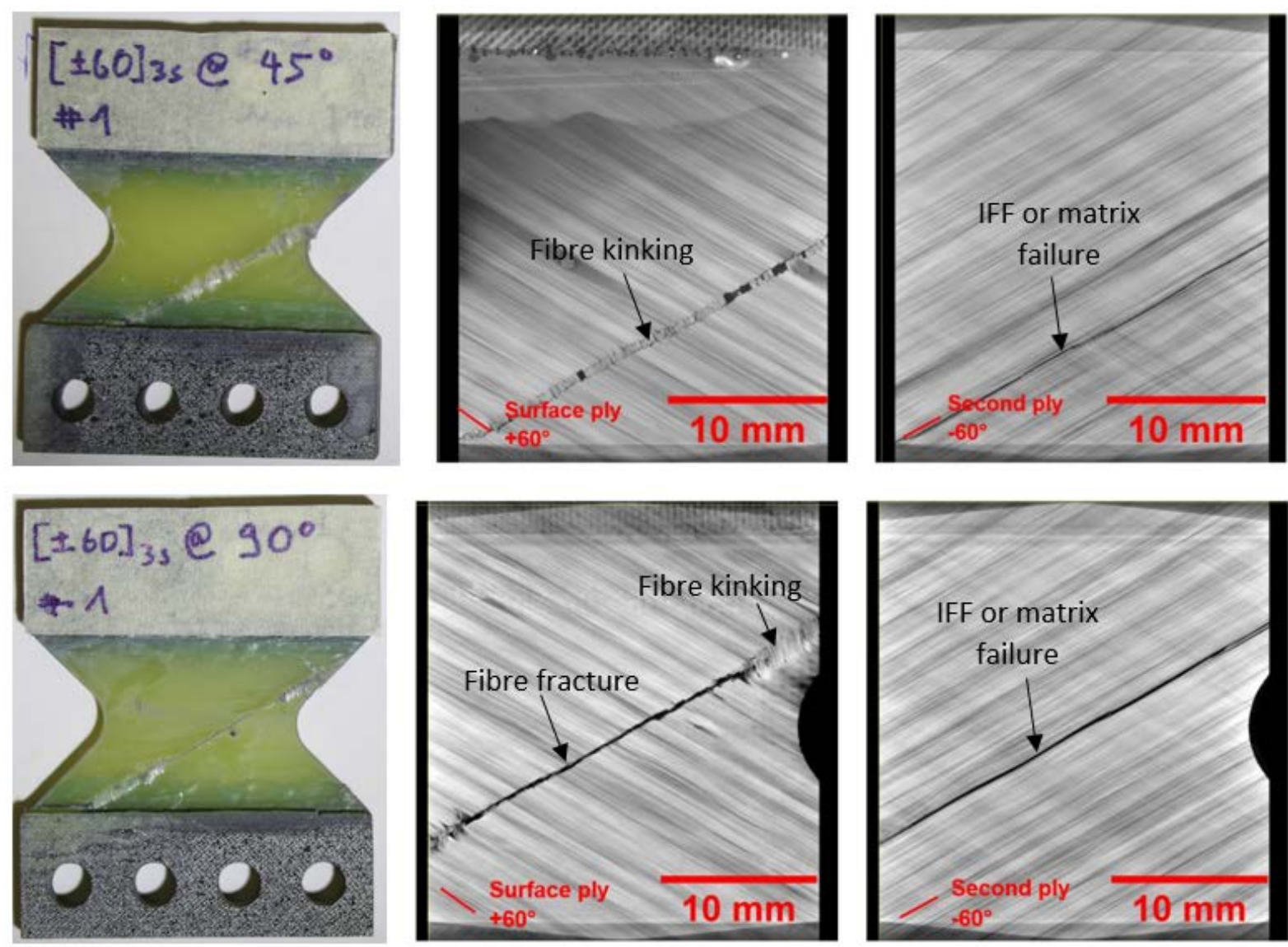

Figure 8: Failure of the [+60/-60]3s specimens under (top row) combined tension-shear $(\alpha=$ $\left.45^{\circ}\right)$ and (bottom row) pure shear $\left(\alpha=90^{\circ}\right)$. CT images of the first two plies in both specimens showing fibre kinking and matrix failure.
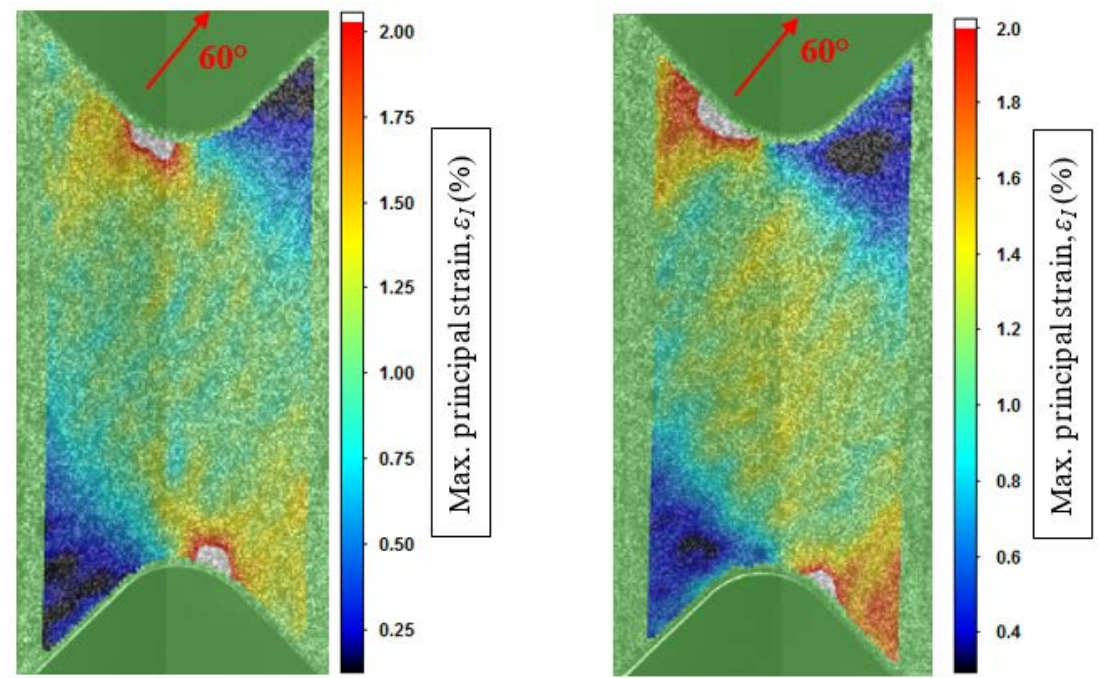

Figure 9: Maximum principal strain, $\varepsilon_{I}$ maps for (left) the combined tension-shear ( $\alpha=45^{\circ}$ ) load configuration at $8.09 \mathrm{kN}$ loading, and (right) the pure shear $\left(\alpha=90^{\circ}\right)$ load configuration at $12.92 \mathrm{kN}$ loading. 

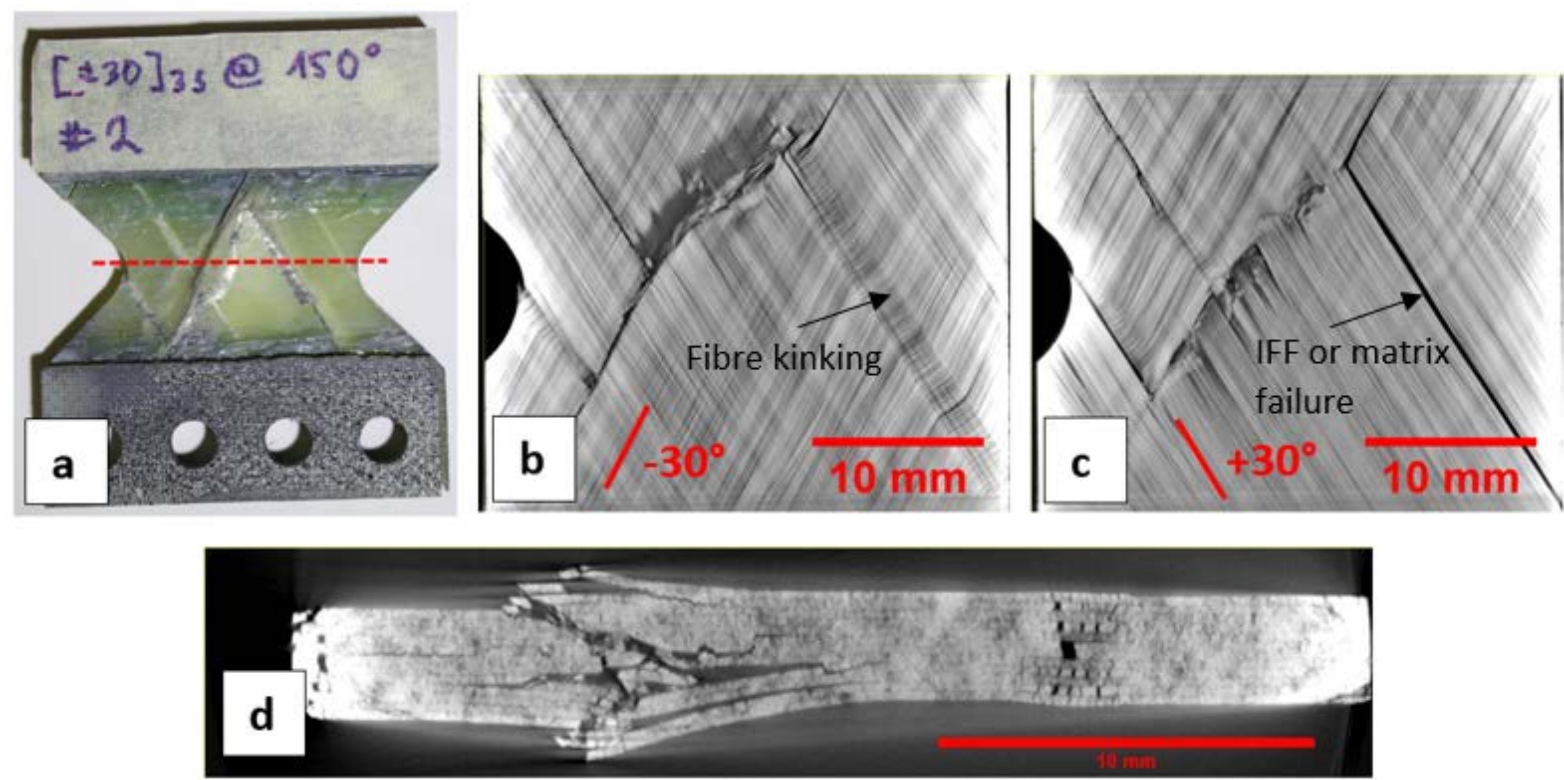

Figure 10: (a) Failure of the $[-30 /+30]_{3 s}$ specimens under combined compression-shear $\left(150^{\circ}\right)$ showing complex crack pattern; (b) CT image of the $-30^{\circ}$ ply showing a fibre kink band along the matrix crack of the adjacent $+30^{\circ}$ ply; (c) CT image of the $+30^{\circ}$ ply showing multiple IFF cracks along the fibre direction; (d) CT images of the specimen along the section highlighted by the dotted line in (a) showing out-of-plane instability leading to catastrophic failure.

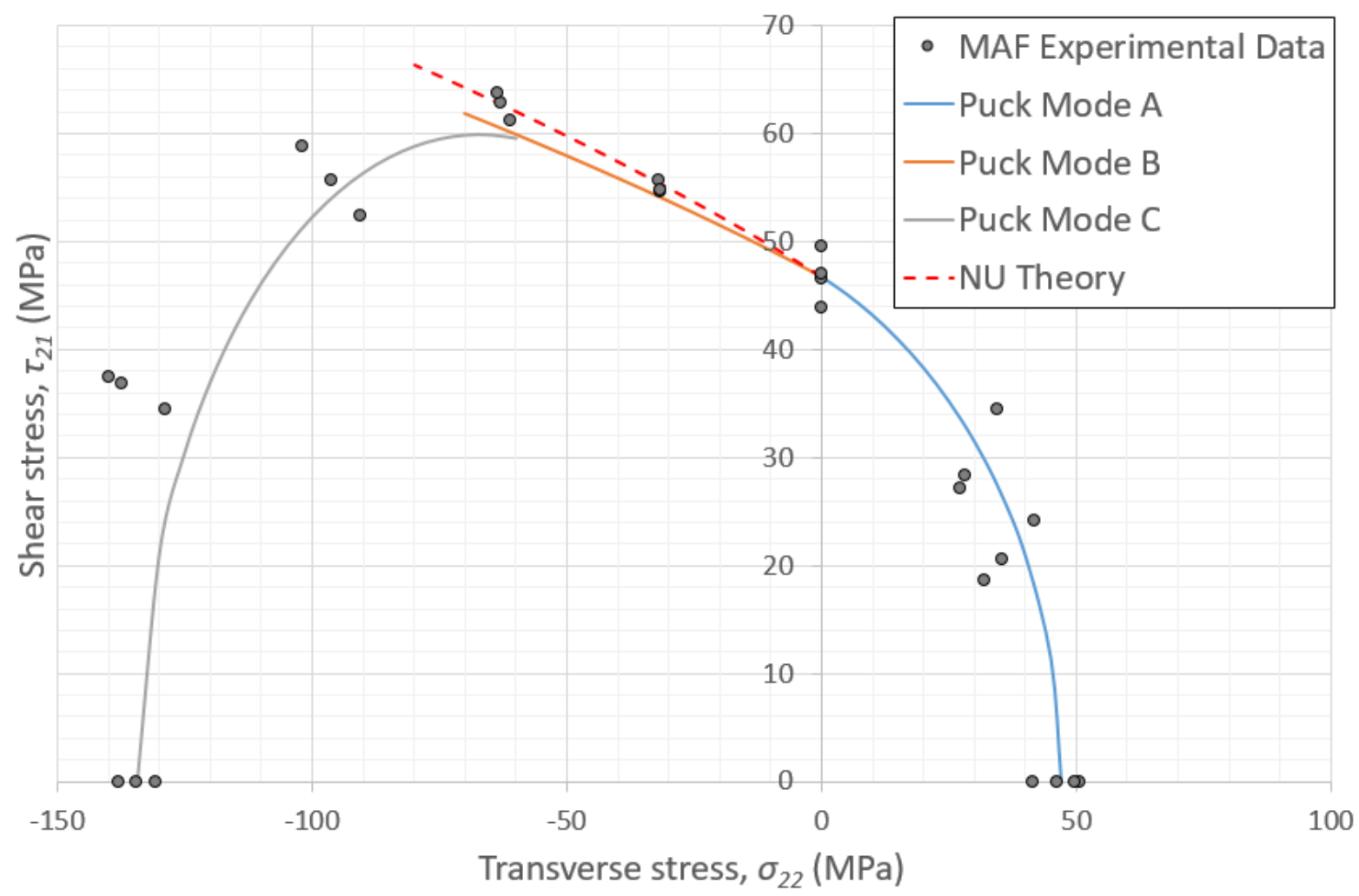

Figure 11: In-plane failure stresses of the [90 $]_{12}$ laminate in the $\sigma_{22}-\tau_{21}$ domain. 


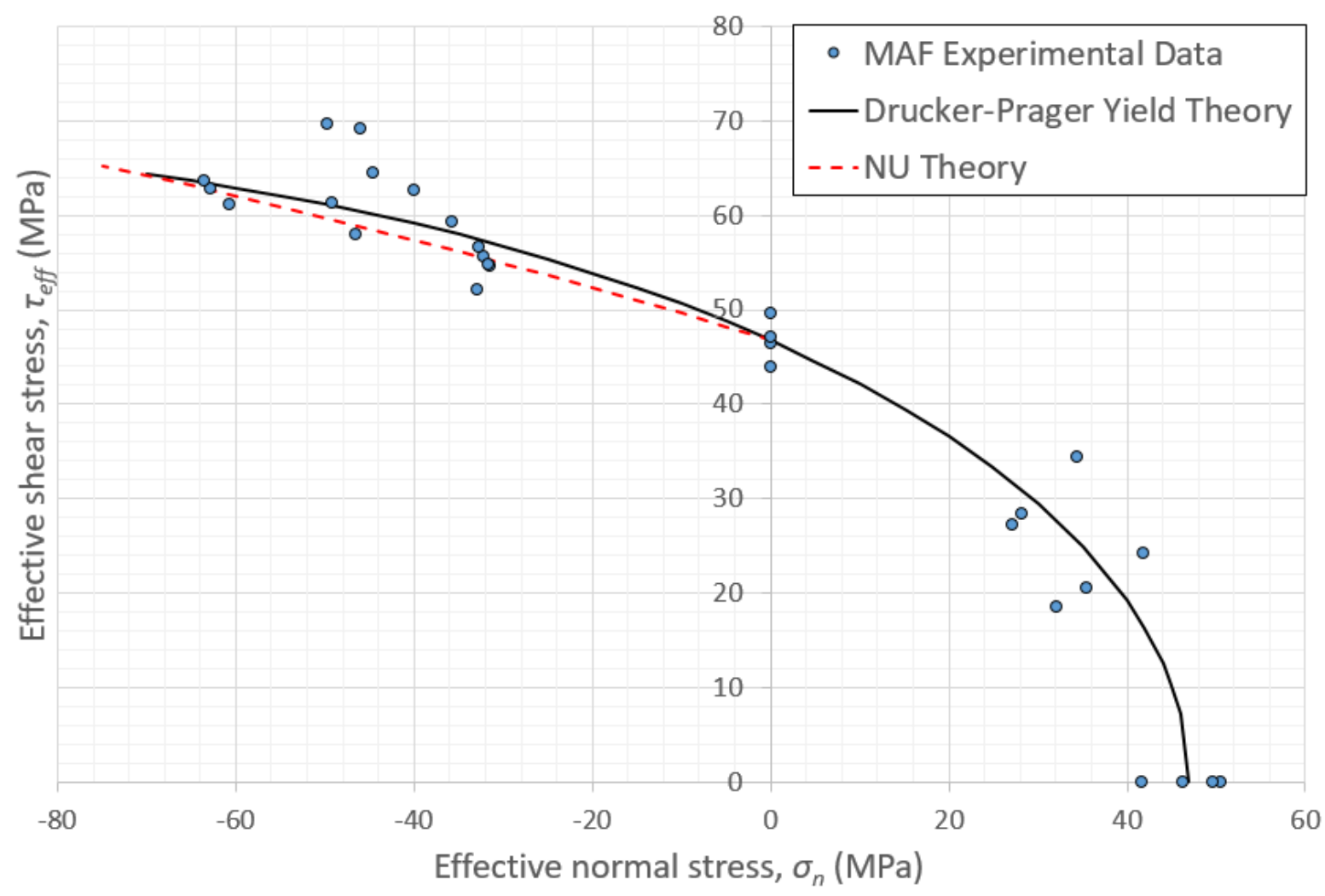

Figure 12: Effective failure stresses on the fracture plane of the [90 $]_{12}$ laminate in the $\sigma_{n}-\tau_{e f f}$ domain.

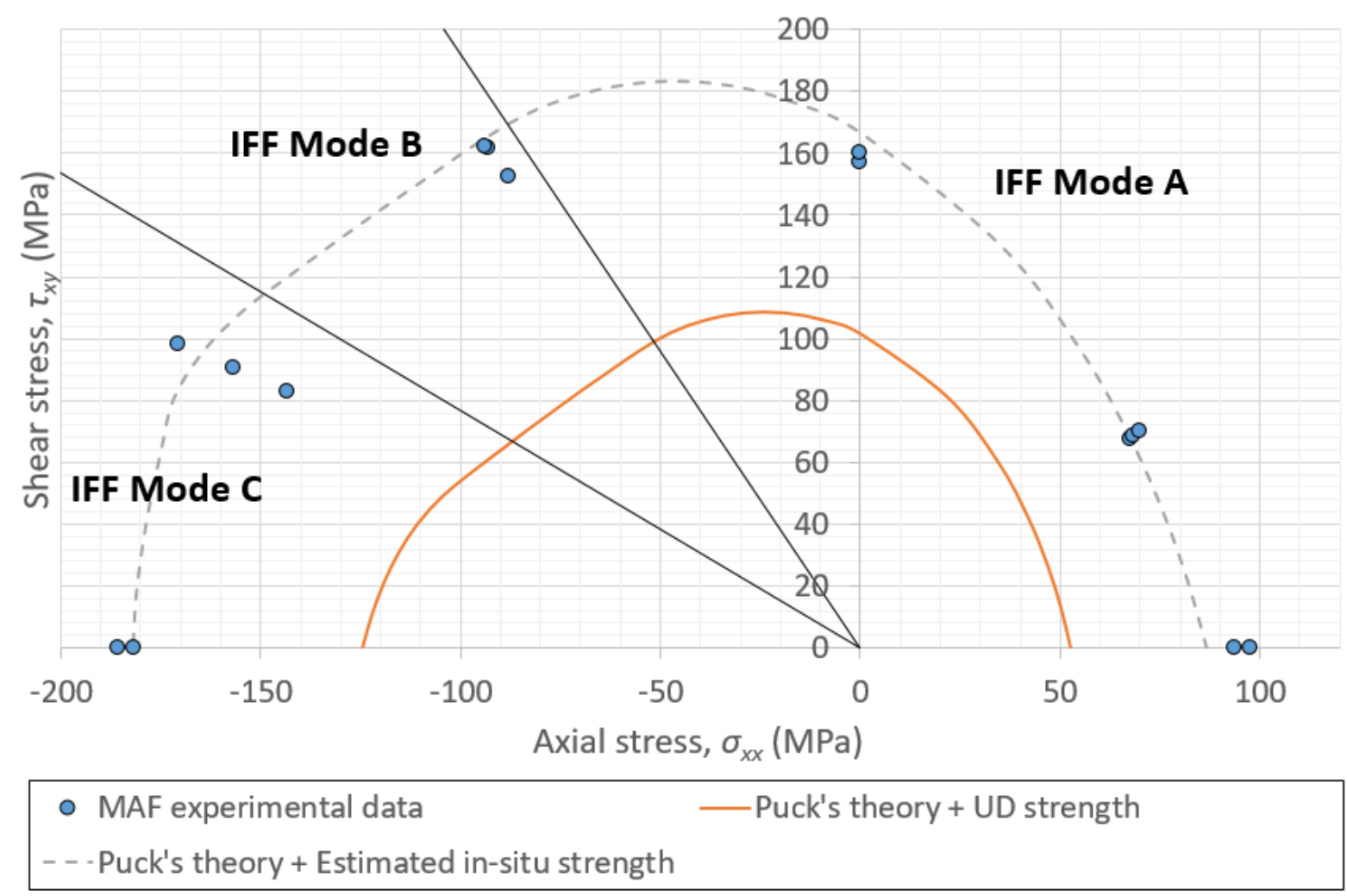

Figure 13: In-plane stresses of the $[+60 /-60]_{3 s}$ laminate in the $\sigma_{x x}-\tau_{x y}$ domain. 
Tables

Table 1: Testing program matrix.

\begin{tabular}{|c|c|c|c|}
\hline $\begin{array}{c}\text { Loading } \\
\text { configuration, } \alpha\end{array}$ & $\sigma_{x x} / \tau_{x y}$ & $\begin{array}{l}\text { Number of } \\
\text { specimens }\end{array}$ & $\begin{array}{c}\text { Specimen waist } \\
\text { width (mm) }\end{array}$ \\
\hline \multicolumn{4}{|c|}{$[0]_{12}$ laminate } \\
\hline $90^{\circ}$ & 0 & 2 & 28.56 \\
\hline \multicolumn{4}{|c|}{$[90]_{12}$ laminate } \\
\hline $0^{\circ}$ & $+\infty$ & 4 & 28.56 \\
\hline $30^{\circ}$ & 1.732 & 3 & 28.56 \\
\hline $45^{\circ}$ & 1 & 3 & 28.56 \\
\hline $90^{\circ}$ & 0 & 4 & 28.56 \\
\hline $120^{\circ}$ & -0.577 & 3 & 28.56 \\
\hline $135^{\circ}$ & -1 & 3 & 28.56 \\
\hline $150^{\circ}$ & -1.732 & 3 & 28.56 \\
\hline $165^{\circ}$ & -3.732 & 3 & 28.56 \\
\hline $180^{\circ}$ & $-\infty$ & 3 & 28.56 \\
\hline \multicolumn{4}{|c|}{$[+60 /-60]_{3 s}$ laminate } \\
\hline $0^{\circ}$ & $+\infty$ & 2 & 25.00 \\
\hline $45^{\circ *}$ & 1 & 3 & 28.56 \\
\hline $90^{\circ *}$ & 0 & 2 & 28.56 \\
\hline $120^{\circ}$ & -0.577 & 3 & 28.56 \\
\hline $150^{\circ}$ & -1.732 & 3 & 28.56 \\
\hline $180^{\circ}$ & $-\infty$ & 2 & 25.00 \\
\hline \multicolumn{4}{|c|}{$[-30 /+30]_{3 s}$ laminate } \\
\hline $45^{\circ}$ & 1 & 2 & 28.56 \\
\hline $90^{\circ}$ & 0 & 2 & 28.56 \\
\hline $120^{\circ}$ & -0.577 & 2 & 28.56 \\
\hline $150^{\circ *}$ & -1.732 & 3 & 28.56 \\
\hline
\end{tabular}

* Specimens which were CT scanned for post-failure inspection. 
Table 2: The average load at failure and the corresponding in-plane normal and shear stresses of [90 $]_{12}$ unidirectional laminate for various load configurations.

\begin{tabular}{|c|c|c|c|c|}
\hline $\begin{array}{c}\text { Load } \\
\text { configuration }(\alpha)\end{array}$ & $\begin{array}{l}\text { Average failure } \\
\text { load (kN) } \\
\text { (c.v.) }\end{array}$ & $\begin{array}{c}\text { Average in- } \\
\text { plane normal } \\
\text { stress } \sigma_{22} \text { at } \\
\text { failure }(\mathrm{MPa})\end{array}$ & $\begin{array}{c}\text { Average in- } \\
\text { plane shear } \\
\text { stress } \tau_{21} \text { at } \\
\text { failure (MPa) }\end{array}$ & $\begin{array}{c}\text { Average } \\
\text { fracture plane } \\
\text { angle, } \theta_{f p}\end{array}$ \\
\hline Pure tension $\left(0^{\circ}\right)$ & $\begin{array}{c}3.77 \\
(8.21 \%)\end{array}$ & 46.98 & 0 & $0^{\circ}$ \\
\hline Tension-shear $\left(30^{\circ}\right)$ & $\begin{array}{c}3.40 \\
(10.12 \%) \\
\end{array}$ & 36.48 & 21.06 & $0^{\circ}$ \\
\hline Tension-shear $\left(45^{\circ}\right)$ & $\begin{array}{c}3.58 \\
(11.27 \%) \\
\end{array}$ & 29.97 & 29.97 & $0^{\circ}$ \\
\hline Pure shear $\left(90^{\circ}\right)$ & $\begin{array}{c}3.90 \\
(4.50 \%)\end{array}$ & 0 & 46.76 & $0^{\circ}$ \\
\hline $\begin{array}{c}\text { Compression-shear } \\
\left(120^{\circ}\right)\end{array}$ & $\begin{array}{c}5.47 \\
(0.38 \%)\end{array}$ & -31.73 & 55.00 & $0^{\circ}$ \\
\hline $\begin{array}{c}\text { Compression-shear } \\
\left(135^{\circ}\right)\end{array}$ & $\begin{array}{c}7.41 \\
(0.80 \%) \\
\end{array}$ & -62.56 & 62.56 & $3^{\circ}$ \\
\hline $\begin{array}{c}\text { Compression-shear } \\
\left(150^{\circ}\right)\end{array}$ & $\begin{array}{c}9.22 \\
(4.05 \%)\end{array}$ & -96.32 & 55.61 & $53^{\circ}$ \\
\hline $\begin{array}{c}\text { Compression-shear } \\
\left(165^{\circ}\right)\end{array}$ & $\begin{array}{c}11.52 \\
(3.44 \%)\end{array}$ & -135.36 & 36.27 & $54^{\circ}$ \\
\hline $\begin{array}{c}\text { Pure compression } \\
\left(180^{\circ}\right)\end{array}$ & $\begin{array}{c}10.74 \\
(3.03 \%) \\
\end{array}$ & -134.47 & 0 & $59^{\circ}$ \\
\hline
\end{tabular}

Table 3: Measured strength and moduli for unidirectional E-glass/RP528 [90 $]_{12}$ laminate.

\begin{tabular}{|l|c|}
\hline \multicolumn{1}{|c|}{ Material property } & Value (c.v.) \\
\hline Transverse tensile modulus, $E_{2}^{T}(\mathrm{GPa})$ & $11.047(0.94 \%)$ \\
\hline Transverse compressive modulus, $E_{2}^{C}(\mathrm{GPa})$ & $12.952(0.38 \%)$ \\
\hline$\left[90^{\circ}\right]$ longitudinal shear modulus, $G_{12}^{90^{\circ}}(\mathrm{GPa})^{*}$ & $3.063(9.98 \%)$ \\
\hline Transverse tensile strength, $Y_{T}(\mathrm{MPa})$ & $47(8.21 \%)$ \\
\hline Transverse compressive strength, $Y_{C}(\mathrm{MPa})$ & $134(4.50 \%)$ \\
\hline$\left[90^{\circ}\right]$ longitudinal shear strength, $S_{12}^{90^{\circ}}(\mathrm{MPa})^{*}$ & $47(3.03 \%)$ \\
\hline
\end{tabular}

* The superscript $90^{\circ}$ is used to differentiate them from $G_{12}$ and $S_{12}$ typically used to denote [0] longitudinal shear modulus and shear strength respectively. 
Table 4: The applied load at failure and the resolved global normal and shear stresses at the gauge section for different load configurations.

\begin{tabular}{|c|c|c|c|c|}
\hline $\begin{array}{l}\text { Load configuration } \\
(\alpha)\end{array}$ & $\begin{array}{c}\text { Average failure } \\
\text { initiation load } \\
\text { (kN) } \\
\text { (c.v.) }\end{array}$ & $\begin{array}{c}\text { Average ultimate } \\
\text { failure load (kN) } \\
\text { (c.v.) }\end{array}$ & $\begin{array}{l}\text { Average in-plane } \\
\text { normal stress } \sigma_{X X} \\
\text { at failure } \\
\text { initiation } \\
\text { (MPa) }\end{array}$ & $\begin{array}{c}\text { Average in-plane } \\
\text { shear stress } \tau_{x y} \text { at } \\
\text { failure initiation } \\
\text { (MPa) }\end{array}$ \\
\hline Pure tension $\left(0^{\circ}\right)^{*}$ & $\begin{array}{c}6.92 \\
(2.02 \%) \\
\end{array}$ & $\begin{array}{c}8.17 \\
(1.59 \%) \\
\end{array}$ & 95.45 & 0 \\
\hline Tension-shear $\left(45^{\circ}\right)$ & $\begin{array}{c}8.03 \\
(1.54 \%)\end{array}$ & $\begin{array}{c}8.32 \\
(3.48 \%)\end{array}$ & 71.03 & 71.03 \\
\hline Pure shear $\left(90^{\circ}\right)$ & - & $\begin{array}{c}13.15 \\
(0.87 \%)\end{array}$ & 0 & 158.71 \\
\hline $\begin{array}{c}\text { Compression-shear } \\
\left(120^{\circ}\right)\end{array}$ & $\begin{array}{c}15.20 \\
(2.79 \%) \\
\end{array}$ & $\begin{array}{c}17.06 \\
(1.68 \%) \\
\end{array}$ & -102.99 & 178.38 \\
\hline $\begin{array}{c}\text { Compression-shear } \\
\left(150^{\circ}\right)\end{array}$ & - & $\begin{array}{c}15.01 \\
(7.13 \%)\end{array}$ & -156.95 & 90.61 \\
\hline $\begin{array}{l}\text { Pure compression } \\
\left(180^{\circ}\right)^{*}\end{array}$ & - & $\begin{array}{c}13.33 \\
(1.09 \%)\end{array}$ & -183.79 & 0 \\
\hline
\end{tabular}

* The width of the second-batch specimen's waist is $25 \mathrm{~mm}$ (instead of $28.56 \mathrm{~mm}$ ).

Table 5: Comparison between $\theta_{f p}$ predicted by Puck’s IFF Mode C and the experimental $\theta_{f p}$.

\begin{tabular}{|c|c|c|c|}
\hline $\begin{array}{c}\text { Loading } \\
\text { configuration }(\boldsymbol{\alpha})\end{array}$ & In-plane $\boldsymbol{\sigma}_{22}$ (MPa) & Experimental $\boldsymbol{\theta}_{f p}$ & $\begin{array}{c}\text { Puck's IFF Mode C } \\
\theta_{f p}=\cos ^{-1}\left(\sqrt{\frac{R_{\perp \perp}^{A}}{-\sigma_{22}}}\right)\end{array}$ \\
\hline $\begin{array}{c}\text { Compression-shear } \\
\left(135^{\circ}\right)\end{array}$ & -62.56 & $3^{\circ}$ & $24^{\circ}$ \\
\hline $\begin{array}{c}\text { Compression-shear } \\
\left(150^{\circ}\right)\end{array}$ & -96.32 & $53^{\circ}$ & $52^{\circ}$ \\
\hline $\begin{array}{c}\text { Compression-shear } \\
\left(165^{\circ}\right)\end{array}$ & -135.36 & $54^{\circ}$ & $51^{\circ}$ \\
\hline $\begin{array}{c}\text { Pure compression } \\
\left(180^{\circ}\right)\end{array}$ & -134.47 & $59^{\circ}$ & \\
\hline
\end{tabular}


Table 6: Material properties used for failure prediction.

\begin{tabular}{|l|c|c|c|c|}
\hline & \multicolumn{2}{|c|}{ E-glass/ RP528 } & \multicolumn{2}{c|}{ E-glass/MY750 [23] } \\
\cline { 2 - 5 } & Unidirectional & $\begin{array}{c}\text { In-situ } \\
\text { (Estimated) }\end{array}$ & Unidirectional & In-situ \\
\hline $\begin{array}{l}\text { Transverse tensile } \\
\text { strength, } Y_{T} \text { (MPa) }\end{array}$ & 47 & 75 & 40 & 113 \\
\hline $\begin{array}{l}\text { Transverse compressive } \\
\text { strength, } Y_{C} \text { (MPa) }\end{array}$ & 134 & 170 & 145 & - \\
\hline $\begin{array}{l}{[90] \text { longitudinal shear }} \\
\text { strength, } S_{12}^{90^{\circ}} \mathbf{( M P a )}\end{array}$ & 47 & 80 & $73^{*}$ & $87^{*}$ \\
\hline
\end{tabular}

* These are values of [0] longitudinal shear strength, $S_{12}^{0^{\circ}}$. 